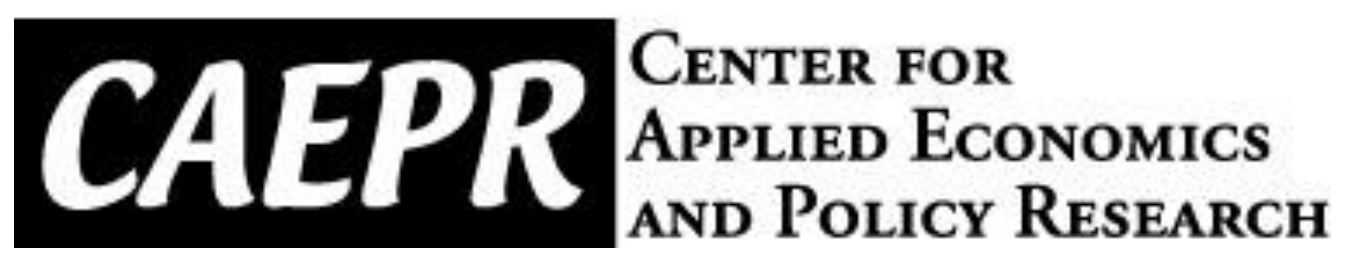

CAEPR Working Paper

\#2011-006

\title{
The Quantity and Quality of Teachers: Dynamics of the Trade-off
}

\author{
Gregory Gilpin \\ Montana State University \\ Michael Kaganovich \\ Indiana University
}

June 14, 2011

This paper can be downloaded without charge from the Social Science Research Network electronic library at: http://ssrn.com/abstract=1868199.

The Center for Applied Economics and Policy Research resides in the Department of Economics at Indiana University Bloomington. CAEPR can be found on the Internet at:

http://www.indiana.edu/ caepr. CAEPR can be reached via email at caepr@indiana.edu or via phone at 812-855-4050.

(C2011 by Gregory Gilpin and Michael Kaganovich. All rights reserved. Short sections of text, not to exceed two paragraphs, may be quoted without explicit permission provided that full credit, including $\odot$ notice, is given to the source. 


\title{
The Quantity and Quality of Teachers: Dynamics of the Trade-off
}

\author{
Gregory Gilpin and Michael Kaganovich ${ }^{\mathrm{b}, \mathrm{c}}$ \\ ${ }^{a}$ Department of Agricultural Economics and Economics, Montana State University, Bozeman, \\ MT, 59718, USA. Phone: (406) 994-5628, gregory.gilpin@ montana.edu \\ ${ }^{\mathrm{b}}$ Corresponding author. Department of Economics, Indiana University, Wylie Hall, Bloomington \\ IN, 47405, USA. Phone: (812)855-6967, fax: (812)855-3736, mkaganov@indiana.edu \\ ${ }^{\mathrm{c}}$ CESifo
}

\begin{abstract}
The paper addresses the two-fold rise in teacher-student ratio in the American K-12 school system in the post-World War II period accompanied by the evidence of a decline in the relative quality of teachers. We develop a dynamic general equilibrium framework for analyzing the teacher quantity-quality trade-off and offer an explanation to the observed trends. Our OLG model features two stages of education: basic and advanced (college), the latter required of teachers. The cost of hiring teachers is influenced by the outside opportunities for college graduates in the production sector. We show that the latter factor strengthens in the process of endogenous growth and that it affects the optimal trade-off between quantity and quality of teachers such that the number of teachers hired will grow over time while their relative, but not the absolute, human capital attainment will fall. This is accompanied by increasing inequality, among the group of college educated workers in particular. We show that this effect, which we call the rising talent premium, applies whether teacher salaries are determined based on merit pay or, alternatively, by collective bargaining. Moreover, the salary compression characterizing the collective bargaining regime has an additional effect exacerbating the loss of the more talented workers by the teaching profession. Further, we analyze a comparative dynamics effect of exogenous skill-biased technological change which raises the college premium. We show that the effect is detrimental to the aggregate quality of teachers and to the quality of basic education. An important insight from this analysis is that in the process of human capital driven economic growth the rise in premium for high ability outpaces that for the average, whereby this effect is accelerated by technological change. This puts a downward pressure on the "real" quality of education inputs and therefore can create a negative feedback effect on human capital development as a factor of economic growth.
\end{abstract}

JEL classification: $\mathrm{H} 52, \mathrm{I} 2, \mathrm{O} 4$

Key words: teacher quality; class size; merit pay; collective bargaining; skill premium; skill biased technological change 


\section{Introduction}

A reduction of class sizes in K-12 schooling has been one of the main education policy priorities in the United States over the last several decades as a means to raising education quality. This is evidenced by the dynamics of student-teacher ratio which fell from 25.8 in 1960 to 15.7 in 2005 . Remarkably, this decline has persisted through the contemporaneous ups and downs of the enrollment dynamics (Digest of Education Statistics, 2007, table 61, reproduced in Table 1 below). Research, however, has shown that students' test scores have not risen despite increased individualized instruction. This has compelled policy makers and researchers to question the role of the quantity of teachers vs. their quality as factors in student performance (see Hanushek et al. (2005)), particularly in light of a possible trade-off between the two.

Indeed the changes in education statistics between 1955 and 2005 displayed in our Table 1 suggest the possibility of a quantity-quality trade-off in the supply of teachers over this period: a remarkable growth in the total number of teachers consistently outpacing the growth of student

Table 1. Historical Data on Public Elementary and Secondary Schools, 1955 to 2005

\begin{tabular}{|c|c|c|c|c|c|c|c|}
\hline Year & Enrollment ${ }^{1, a}$ & Teachers $^{1, a}$ & $\begin{array}{c}\text { Pupil / teacher } \\
\text { ratio }^{1}\end{array}$ & $\begin{array}{c}\text { Real } \\
\text { Expenditures } \\
\text { per Pupil }^{4 e}\end{array}$ & $\begin{array}{l}\text { Expenditures } \\
\text { per Pupil }^{4}\end{array}$ & $\begin{array}{l}\text { Expenditures } \\
\text { to } \mathrm{GDP}^{2, \mathrm{~b}}\end{array}$ & $\begin{array}{c}\text { Relative Teacher } \\
\text { Salary }^{3, \mathrm{~b}, \mathrm{~d}}\end{array}$ \\
\hline 1955 & 30,680 & 1,141 & 26.9 & 234.2 & 294.2 & $3.3^{c}$ & \\
\hline 1960 & 36,281 & 1,408 & 25.8 & 2606.3 & 375.1 & 3.6 & 43.0 \\
\hline 1965 & 42,173 & 1,710 & 24.7 & 3440.0 & 537.7 & 3.9 & \\
\hline 1970 & 45,894 & 2,059 & 22.3 & 4682.1 & 911.1 & 4.6 & 44.0 \\
\hline 1975 & 44,819 & 2,198 & 20.4 & 5534.6 & 1503.6 & 4.6 & \\
\hline 1980 & 40,877 & 2,184 & 18.7 & 5895.3 & 2501.6 & 4.0 & 41.0 \\
\hline 1985 & 39,422 & 2,206 & 17.9 & 7045.4 & 3755.6 & 3.8 & \\
\hline 1990 & 41,217 & 2,398 & 17.2 & 8014.7 & 5257.8 & 4.3 & 35.0 \\
\hline 1995 & 44,840 & 2,598 & 17.3 & 8121.8 & 6146.9 & 4.3 & \\
\hline 2000 & 47,204 & 2,941 & 16.0 & 9214.8 & 7903.7 & 4.5 & 36.5 \\
\hline 2005 & 49,113 & 3,137 & 15.7 & 10041.5 & 9788.4 & 4.6 & \\
\hline \multicolumn{8}{|l|}{ Source: } \\
\hline \multicolumn{8}{|c|}{${ }^{1}$ Digest of Education Statistics 2007, Table 61.} \\
\hline \multicolumn{8}{|c|}{${ }^{2}$ Digest of Education Statistics 2007, Table 25.} \\
\hline \multicolumn{8}{|c|}{${ }^{3}$ Hanushek \& Rivkin (2003). } \\
\hline \multicolumn{8}{|c|}{${ }^{4}$ Digest of Education Statistics 2007, Table 32.} \\
\hline \multicolumn{8}{|l|}{ Notes: } \\
\hline \multicolumn{8}{|c|}{${ }^{a}$ In thousands. } \\
\hline \multicolumn{8}{|c|}{${ }^{\mathrm{b}}$ In Percent. } \\
\hline \multicolumn{8}{|c|}{ c 1959 data. } \\
\hline \multicolumn{8}{|c|}{${ }^{d}$ College educated females, age $20-29$, earning less than average female teacher, age $20-29}$. \\
\hline${ }^{\mathrm{e}} \mathrm{De}$ & ated by $\mathrm{CPI}$ and in & 2006 dollars. & & & & & \\
\hline
\end{tabular}

enrollments was accompanied by declining relative teacher salaries, despite essentially steady overall K-12 public education expenditures as a share of GDP since 1970. Another significant trend observed over about the same period is the decline in the aptitude of teachers relative to 
other educated workers. Hoxby and Leigh (2004) estimate that in $196341 \%$ of all teachers were of the "middle" aptitude relative to their educated peers, with $17 \%$ above and $42 \%$ below the average; by comparison, in 2000, 28\% of all teachers were of the "middle" aptitude with $5 \%$ above and $67 \%$ below average. Corcoran et al. (2004) provide similar results.

Much of the empirical literature analyzing the factors of student performance focuses on estimating the returns to either quality or quantity of teachers while attempting to control the other variable. For example, Aaronson et al. (2007), Clotfelter et al. (2007), Rivkin et al. (2005), Goldhaber and Anthony (2007)) estimate the effect of teacher characteristics on student achievement while partially controlling the class size based on geographic and time variation of class size mandates. The second empirical strategy aims to estimate how class size affects student achievement while attempting to control for teacher quality. Angrist and Lavy (1999), Krueger and Whitmore (2001), Krueger (1999), Jepsen and Rivkin (2002) work with data from policy experiments producing random assignment of students to smaller and larger classes to obtain unbiased estimates of the effects of class size on student achievement controlling for teacher quality. Using data from North Carolina, Clotfelter et al. (2007) conclude that teacher experience, test scores, and regular licensure all have greater positive effects on student achievement, whether compared to the effects of changes in class size or to the socioeconomic characteristics of students. However, Goldhaber and Anthony (2007) using the same North Carolina data find that the evidence is mixed on whether improved observable teacher credentials have positive impact on student achievement. These results are similar to Rivkin et al. (2005) who use the Texas data from UTD Texas Schools Project. On the other hand, Angrist and Lavy (1999) use Israel's mandated class size limits to estimate class size effects on student achievement. They find that reducing class size causes significant and substantial increase in test scores for fourth and fifth graders, although not for third graders. Krueger (1999) analyzes data from Tennessee Project STAR and finds that students' scores on standardized tests increase by four percentage points in the first year they attend smaller classes while in subsequent years the test scores grow by about one percentage point per year. These findings are, however, challenged by Hanushek (1999) who suggests that the project design has resulted in the upward bias in the data in favor of the class size effect.

Thus the results of the empirical literature do not seem to provide a conclusive justification for the policy focus on reducing teacher-pupil ratio, on the grounds of benefits to 
student performance. This appears to be due in part to the fact that the pursuit of this policy has been accompanied by a decline of teacher quality, at least in relation to their college-educated peers. In fact, the presence of this quantity-quality trade-off in the dynamics of the two variables evokes the challenge of endogeneity in the estimation exercises. Indeed, in response to Card and Krueger (1992) finding, based on longitudinal data, of positive effect of decreasing class size on student performance, Jepsen and Rivkin (2002) argue that using mandated class size reduction programs as natural experiments for estimating the class size effect is problematic when these changes are accompanied by a trade-off between the quantity and quality of teachers, since it is likely to be endogenous. They point out that California's class size reduction program came at the expense of hiring lower quality teachers to staff additional classrooms, which offset the benefits of smaller classes. Similarly, Hoxby (1996) finds that in unionized public school higher measured inputs may produce no gains to student achievement: the teachers' unions engage in rent-seeking which leads to lower productivity, via teacher quality or effort, enough to offset any gains from the additional resources, smaller student-teacher ratios in particular.

Thus, despite a significant attention in the literature, the understanding of the striking structural change in the allocation of educational resources over the recent decades remains incomplete. This underscores the need for a broader theoretical framework, which would capture the dynamic interaction between inputs in education as it is influenced by the labor market in the production economy. We note in this regard a branch of recent literature which has studied how outside job market opportunities have affected the quality of teachers. Flyer and Rosen (1997) report that the three-fold increase in direct costs of education per student is attributable to the growing market opportunities for women. Hanushek and Rivkin (1997) document the decline in the earnings of women teachers relative to women in other occupations and suggest that the expansion of alternative opportunities reduced teacher quality. Hanushek and Rivkin (2004) estimate that in 1955, 50\% of all educated male workers earned less than male teachers, compared to $36 \%$ in 2000 . Likewise, in 1955 , $48 \%$ of all educated female workers earned less than female teachers compared to $29 \%$ in 2000. Similar analyses concerning the effect of the outside work opportunities on teacher quality are offered by Goldhaber and Liu (2003), Stoddard (2003), and Bacolod (2007). Lakdawalla (2006) demonstrates that a rising skill premium of educated workers due to faster technological change coupled with low productivity growth of skilled teachers, has led to the substitution toward a larger quantity of unskilled teachers, away 
from the increasingly expensive skilled teachers.

Our paper develops a theoretical framework for analyzing the teacher quantity-quality trade-off and offers an explanation to the observed trend biased in favor of quantity. We present a model which incorporates the factors of education quality discussed above, in a dynamic general equilibrium framework where education policy decisions affect and are affected by individual education and employment decisions, whereas the dynamics of human capital accumulation and labor productivity has a feedback effect on both. In our model, a public education agency wishes to maximize the quality of basic education per student and, due to a budget constraint, faces a trade-off between the quality and quantity of teachers to be hired. We explore the following factors that may affect this trade-off: (i) the opportunity cost of teachers in terms of potential earnings in the alternative occupations in the production economy, and its evolution in the process of economic growth; (ii) collective bargaining driven by teacher unions as an institutional factor leading to wage compression among teachers; (ii) the rise of skill premium resulting from technological change, which affects the opportunity cost of teachers.

It is, indeed, well documented that teacher unions significantly contribute to the phenomenon of compression of seniority adjusted wages: unions provide tenure to teachers and tie their salary primarily to experience rather than performance; administrators wishing to hire higher quality teachers are forced by the unions to then provide matching raises to teachers across the board. ${ }^{1}$ Furthermore, the wage compression in public schools imposes similar wage rigidity on the private school teacher market (Lakdawalla, 2006).

In our model, basic education is publicly funded through an income tax, whose rate is set exogenously, and is administered by an education agency which allocates these funds while deciding on the levels of teacher salaries and the number of teachers to be hired. The model features two stages of education: basic and advanced (college), the latter being required of teachers. College graduates can also take jobs in the skilled labor force of the production sector and get paid a competitive wage according to their human capital attainment. This opportunity cost implies that the levels of teacher salaries set by the education agency will determine the

\footnotetext{
${ }^{1}$ It should be noted that unionization is not the sole factor responsible for the compression of teacher salaries. It is also due in part to the difficulty of measuring teacher productivity, especially in terms of educational value added given the unobservable student characteristics as well as student sorting into classes.
} 
quality (human capital levels) of teachers who can be hired. Thus the total cost of hiring teachers is affected in our model by the outside opportunities available to skilled individuals in the production sector. We show, moreover, that in the process of endogenous growth this effect strengthens and that it pushes the optimal trade-off between quantity and quality of teachers in the direction of the former. Namely, in the face of rising over time cost of highly able skilled workers, the education agency will find it optimal to opt for increasing the number of teachers hired while reducing the overall relative quality of the pool of teachers. (The absolute human capital attainment of teachers, however, will rise along with the overall human capital accumulation, while sliding toward the lower tail of the distribution of college educated population.) Furthermore, we show that this human capital dynamics is characterized by increasing inequality within the group of college educated workers as well as between it and the unskilled.

In order to assess the role of an institutional factor in the teacher quantity-quality tradeoff, we consider two alternative teacher employment regimes: the "merit pay" regime where each teacher's salary is based on his human capital attainment, as well as the "collective bargaining" regime where the education agency is bound by salary contracts with teacher unions which compress teacher salaries. Our results show that the salary compression due to the collective bargaining further exacerbates the loss of the more talented workers by the teaching profession and thus additionally contributes to the decline of teacher quality.

We then build on these results to further analyze the impact of exogenous technological change biased toward skill, i.e., augmenting productivity of skilled workers and thereby the college premium. We show that such technological change will exacerbate the negative trends in the quality of basic education in relation to GDP growth. Specifically, the comparative dynamics effect (relative to the benchmark trajectory) will be detrimental to the aggregate quality of teachers as well as to the quality of basic education, due to the upward shocks to the cost of skilled labor. This is consistent with the aforementioned observation by Lakdawalla (2006) as well as the discussion by Rangazas (2002) of Baumol's Disease in education sector as a result of technological change driving up the sector's real labor costs, which leads him to conclude that school expenditures must be deflated by the rate of technological change in addition to the rate of inflation. Our model adds a dimension to this understanding: we show that in the process of human capital driven economic growth the rise in premium for high ability will outpace that for 
the average even besides the effect of technological change, hence an additional downward pressure on the "real" quality of education inputs.

Thus this paper offers a theory explaining the trend in education policy in favor of lower student-teacher ratios (i.e., higher quantity of teachers) combined with deteriorating teacher quality, despite growing per student schooling expenditures.

The paper is organized as follows. Section 2 develops a dynamic general equilibrium model of production economy and two-stage formation of human capital. In Section 3, we introduce the benchmark model of the administration of basic education with merit pay for teachers and then define and prove the existence of the recursive dynamic equilibrium. Section 4 extends the analysis to the collective bargaining regime for teachers; Section 5 delivers the main results on the dynamics of the quantity and quality of teachers for this case. Section 6 compares the teacher quantity-quality dynamics under the collective bargaining and merit pay regimes. Section 7 concludes. Appendix 1 contains most of the proofs while Appendix 2 presents a glossary of notation.

\section{The Model}

We develop a general equilibrium growth model of an economy populated by overlapping generations of individuals whose life consists of three periods: childhood, young adulthood, and old age. We identify a generation with the period when its members are young adults, thus the individuals born in period $t-1$ form a generation $G_{t}$. We assume that population size is constant in each generation $G_{t}$ and that it forms a continuum on the interval $[0,1]$. Let $\mu($.$) be the$ induced Lebesgue measure on this set, so that $\mu([0,1])=1$ for all $t$.

Children make no decisions of their own and receive basic (or first stage) education which is provided publicly. Young adults are endowed with a unit of time and face an option of devoting a fixed fraction $n$ of it to acquiring advanced education (which we will also refer to as college or second stage education); the balance of time not spent on education is inelastically devoted to work. Specifically, the individuals without college education will work for the full unit of time in the "unskilled" production workforce. Those with college education either work for the remaining fraction of time $1-n$ in the "skilled" production workforce or, if qualified by the education authority, can work as public school teachers. Individuals derive income from 
work. They spend part of it on consumption when young and invest the rest to use the returns to finance their consumption in retirement, the last period of life.

\subsection{Production}

The production sector of the economy consists of perfectly competitive firms producing a homogeneous consumption good by means of a technology which uses two factors of production -- unskilled and skilled human capital. The aggregate production function is given by ${ }^{2,3}$

$$
Y_{t}=w\left(L_{t}+\theta_{t} H_{t}^{y}\right)
$$

where $w>0$, while $L_{t}, H_{t}^{y}$ stand, respectively, for the aggregate supply of unskilled human capital and skilled human capital employed in the production sector in period $t$. The coefficient $w$ is thus a fixed productivity parameter per unit of unskilled labor. The coefficient $\theta_{t}$ characterizes the net productivity augmentation of skilled human capital (adjusted for the shorter employment duration due to the time spent in college) which is imbedded in technology. The sequence of $\left\{\theta_{t}\right\}_{t=o}^{\infty}$ characterizing the evolution (or stationarity, as a special case) of the skill premium in the process of technological change is assumed to be exogenously given.

\subsection{Households}

The economy is populated by overlapping generations $G_{t}, t=0,1, \ldots$ of agents whose lives consist of two periods, childhood and adulthood, where the time index $\mathrm{t}$ of a generation refers to the time of its adulthood. While everyone's childhood is devoted to receiving universal basic education, all adult individuals $\omega$ of each generation $G_{t}$ work and consume their post-tax income $\left(1-\tau_{t}\right) I_{t}(\omega)$, where $I_{t}(\omega)$ is the individual's wage income derived from human capital and $\tau_{t}$ is the uniform rate of labor income tax collected by the government whose only outlay is funding basic public education. We leave the process by which the tax rates are determined outside the scope of this study and assume that $\tau_{t}$ are exogenous and may either be constant or vary over

\footnotetext{
${ }^{2}$ See Appendix 2 for the glossary of notation.

${ }^{3}$ An earlier version of the paper, Gilpin and Kaganovich (2009), featured production technology where physical capital financed by household savings was the third input. The present simplification, while streamlining the exposition, preserves our main results.
} 
time (see a discussion of a rationale for the latter possibility in the concluding Section 7).

According to production function (1) individuals working in the production of goods receive the wage at competitive rates $w$ and $\theta_{t} w$, respectively, per unit of their unskilled or skilled human capital, whichever applies. Thus the income of individual $\omega$ who receives only basic education and attains the level of unskilled human capital $l_{t}(\omega)$ will be

$$
I_{t}(\omega)=w l_{t}(\omega)
$$

The individual $\omega$ who obtains college education, attains the level of skilled human capital $h_{t}(\omega)$ and is employed in the production sector, will receive income

$$
I_{t}(\omega)=\theta_{t} w h_{t}(\omega)
$$

The incomes of college educated individuals who become teachers will be specified later.

According to the above description, the only decisions faced by the households concern (i) the level of educational attainment: basic or college, and (ii) in the latter case, a career choice between production of goods and teaching. We assume that income maximization is the households' sole motive in making these decisions.

\subsection{Human Capital Formation}

The human capital received by each child $\omega$ of generation $G_{t}$ at the first (basic) stage of his education is produced in period $t-1$ by combining children's random innate ability with public education according to

$$
l_{t}(\omega)=C a(\omega) E_{t-1}
$$

where $C$ is a positive constant, $E_{t-1}$ is a uniform quality of public schooling received by each child in period $t-1$ while $a(\omega)$ is the child's innate ability.

Assumption 1 Innate ability $a(\omega)$ is distributed independently and identically in each generation (the time indexation is thus omitted); the distribution is uniform in the interval [0, A].

The uniform distribution assumption, which we make following Galor and Moav (2000), is aimed at obtaining similarly tractable analytical results but is not essential for the overall intuition.

We will now introduce the human capital production function for the advanced (college) 
stage of education. Consistent with Ben-Porath (1967) and Rosen (1976) we assume that the gains from college education depend on one's prior preparation, which in turn depends on the innate ability. Moreover, we assume that college education has a pre-requisite human capital threshold $h^{*}$. Rather than an ad hoc admission requirement (we assume that all individuals are free to choose to go to college but base this decision purely on income considerations) we view this threshold as a set of benchmark skills, such as adequate language and mathematical proficiency whose deficit would preclude any benefit from learning at the advanced stage. ${ }^{4}$ Specifically, we postulate that if an individual $\omega$ of generation $G_{t}$ chooses to go to college, he will become a "skilled" agent with the level of human capital given by

$$
h_{t}(\omega)=b l_{t}(\omega)+B\left[l_{t}(\omega)-h^{*}\right]
$$

where $b \in(0,1)$ and $B>0$ are given constants. Thus according to the expression (5) the gains from college education depend on the extent to which the individual's pre-college human capital attainment $l_{t}(\omega)$ exceeds the threshold $h^{*}$.

The college education production function (5) also reflects a partial loss of pre-college human capital, according to the coefficient $b$, for the purposes of skilled human capital. This loss includes the opportunity cost of the time spent in college. While this loss is counteracted by the net productivity augmentation $\theta_{t}$ of skilled human capital according to the economy's production function (1), we impose a condition

$$
b \theta_{t}<1
$$

which indeed implies that individuals whose pre-college human capital $l_{t}(\omega)$ is below, at, or even slightly above the threshold $h^{*}$, will not gain from attending college and therefore will not choose to do so. It is likewise logical to assume that highly able individuals, particularly those

\footnotetext{
${ }^{4}$ See Su (2004) for a similar approach to college eligibility. One can envision that this knowledge threshold may evolve over time with changes in learning technology. For example, it now tends to incorporate computer literacy; while applicants are not tested on it for admission decisions, their progress in many college specialties will critically depend on it. For the purposes of our analysis $h^{*}$ is assumed fixed. Note the important distinction between this knowledge threshold, which determines a student's true performance, and the concept of an ad hoc admission threshold addressed in the "educational standards" literature, such as Betts (1998), an education policy variable that serves as a sorting device and employability signal.
} 
with the highest ability level A, will benefit from attending college. According to equations (4) and (5) this will be true in generation $G_{t}$ if and only if the following inequality holds:

$$
(b+B) C A E_{t-1} \geq B h^{*}
$$

In Section 4, and in more detail in Appendix 1, we will state parametric assumptions which in particular ensure that the above inequality does hold at all times.

According to the expressions (4) and (5) human capital attainment, and therefore the corresponding income level, is an increasing function of the innate ability. Therefore if a certain individual decides to attend college then all agents with higher ability will also do so. Thus in each period $t$ there is an ability cut-off level $a_{t}^{*}$ such that an individual $\omega$ in generation $t$ will choose to attend college if and only if his ability $a(\omega)$ exceeds $a_{t}^{*}$. Without the loss of generality we'll make a convention that individuals with ability level $a_{t}^{*}$ do choose to go to college. We will later show that this college attendance ability cut-off level is given by the formula

$$
a_{t}^{*}=\frac{1}{C E_{t-1}} \frac{\theta_{t} B h^{*}}{\theta_{t}(b+B)-1}
$$

which has a straightforward meaning: an individual will choose to attend college if and only if his wage income derived from skilled human capital given by formula (5) and adjusted for the exogenous productivity augmentation $\theta_{t}$ will exceed his wage based on the unskilled human capital obtained at the first stage of education according to its production function (4).

The kinked form of the college human capital production function (5), combined with pre-college preparation given by (4), implies that individual's advanced human capital attainment exhibits increasing returns to ability, for which the quality of basic publicly provided education is a complementary input. This allows us to capture an important and arguably realistic property of the talent premium of college education: the skill upgrade that it provides to a highly able student is disproportionately larger than the one gained by a less able peer. Furthermore, while higher quality public basic education "lifts all boats", more able students will derive disproportionately greater benefits from it. This rising talent premium argument is used in some of the recent literature to explain the evidence of increasing dispersion of earnings. For example, Huggett et al. (2006) use life-cycle framework with a multi-stage Ben-Porath type model of human capital accumulation, which exhibits increasing returns to ability at higher stages of education, to explain the evolution of wage dispersion in the U.S. Another strand of models 
represented by Galor and Zeira (1993) is able to explain intergenerational persistence of inequality by the presence of credit constraints. The underlying mechanism, however, is fundamentally similar to ours: the consequence of the borrowing constraints is that investment in education exhibits increasing returns to agents' endowments (within a certain range). ${ }^{5}$ Restuccia and Urrutia (2004) use a calibrated model which includes explicit early and college stages of education to apportion the factors, including individual ability and borrowing constraints, responsible for the intergenerational persistence of income inequality. By contrast, in most models of public education, such as by Glomm and Ravikumar (1992), human capital accumulation exhibits decreasing returns to private inputs, which leads to vanishing relative variation of income. ${ }^{6}$

\subsection{Quality of Basic Education}

We shall now introduce the per student basic education quality $E_{t}$, i.e. the public input in the basic education production function (4) provided in period $t$, as a function of the quality and quantity of teachers chosen by a public education agency. Recall that only college educated individuals are eligible to be employed as teachers. Let $\Sigma_{t}$ be the set of individuals $\omega$ in generation $t$ employed as teachers. Let $z_{t}$ be the total number of teachers. Since population size is normalized to 1 in all generations, $z_{t}$ is also the fraction of teachers in the overall population in generation $t$, as well as the teacher-student ratio for generation $t+1$ students.

We define the aggregate teacher quality as the aggregate human capital of teachers

$$
q_{t}=\int_{\omega \in \Sigma_{t}} h_{t}(\omega) d \mu_{t}(\omega)
$$

Likewise, the average teacher quality is given by $z_{t}^{-1} \int_{\omega \in \Sigma_{t}} h_{t}(\omega) d \mu_{t}(\omega)=z_{t}^{-1} q_{t}$. The explicit

\footnotetext{
${ }^{5}$ Cunha and Heckman (2007) and related recent work appear to provide a unified framework for these approaches.

${ }^{6}$ The model used by Laitner (2000) also features decreasing return to private investment in education, but this return is enhanced by a higher individual ability as well as exogenous technological change. As a result, private investment in education rises with one's ability; moreover, the ability premium rises, in absolute terms, in the process of technological change.
} 
account for the heterogeneity of teachers' human capital attainment reflected in this formula is obviously an essential element of our model. Eckstein and Zilcha (1994), to our knowledge the first to explicitly incorporate teacher human capital as an input in (compulsory) schooling, assumed that it equals to the average human capital of their generation. ${ }^{7}$

We now define per student quality of basic education as a Cobb-Douglas function of the quantity and aggregate quality (human capital) of teachers:

$$
E_{t}=z_{t}^{\gamma} q_{t}^{v}
$$

with positive coefficients $\gamma, v$. The essence of this education quality production function is that $\gamma>0$ implies a distinct effect of the class size (equivalently, that of teacher-student ratio) in addition to the aggregate human capital of teachers on student achievement, and therefore recognizes a trade-off between the quantity and quality of teachers in education production ${ }^{8}$ consistent with much of the empirical evidence. Indeed, postulating $\gamma>0$ in (8) is necessary for the analysis to be consistent with US time series data on teacher quantity and quality: as will become clear from our analysis, if $\gamma=0$ was the case, teacher labor markets would not exhibit a bias in favor of quantity. In fact, it can be shown that the opposite would take place under teacher salary compression due to collective bargaining (which is a predominant feature of the U.S. teacher labor market): the inherent deadweight loss would be minimized and the education quality maximized (subject to a budget constraint) by obtaining the requisite aggregate human capital amount with hiring fewer but more skilled teachers, i.e., from the top segment of the ability distribution. Overwhelming evidence to the contrary is presented by the empirical literature we discussed in the Introduction, including Hoxby and Leigh (2004) who estimate that $67 \%$ of public school teachers are below the average aptitude of their college cohort, as well as

\footnotetext{
${ }^{7}$ Hatsor (2008) contrasts such regime, which implies that teachers are selected at random from the population, with the one where the quality of teachers is an optimal policy decision traded off against their quantity. She focuses on comparing the implications of these regimes for growth and welfare in the framework of strategic interaction between the education and budgeting authorities of the government.

${ }^{8}$ This concept is similarly at the core of the education production functions used by Tamura (2001) to study the contribution of education to the observed conditional convergence of incomes across the US states, Stoddard (2003) who examined the effects of changes in the labor market for women on the teacher labor market, and Lakdawalla (2006) in his analysis of the effect of technological change on the skilled labor force and teacher labor market.
} 
Hanushek and Rivkin (2004), Goldhaber and Liu (2003), Stoddard (2003), and Bacolod (2007) who obtain analogous estimates using the earnings data.

Since the human capital of teachers is the only potentially unbounded educational input in our model, which is in this respect similar to human capital production in Lucas (1988), we must likewise require non-decreasing returns to this factor alone, i.e. $v \geq 1$, in order to also ensure that the model can exhibit aggregate growth of human capital across generations.

The special case of (8) with $\gamma=v=1$, i.e., $E_{t}=z_{t} \int_{\omega \in \Sigma_{t}} h_{t}(\omega) d \mu_{t}(\omega)$ has a particularly straightforward interpretation. Assume that all teachers are perfectly sorted across classes, each of equal size $z_{t}^{-1}$, such that each student is exposed through his classes to a cross-section of teachers perfectly representing their distribution of quality. Then the above expression, which is equivalent to $E_{t}=\int_{\omega \in \Sigma_{t}} \frac{h_{t}(\omega)}{z_{t}^{-1}} d \mu_{t}(\omega)$, can be interpreted as per student average teacher quality.

\subsection{Administration of Basic Education}

The basic level of schooling is administered by a public education agency with the goal of maximizing its quality $E_{t}$, as defined by the expression (8) above, subject to the budget constraint given by the revenue from a uniform labor income tax at a flat rate $\tau_{t}{ }^{9}$ To this end in each period $t$, the agency must decide on the number of teachers to be hired $z_{t}$ and must set teacher salaries. The latter will also determine the quality of the teachers hired, i.e., the segment $\Sigma_{t}$ of the distribution of college-educated individuals who will become teachers, but this relationship depends on the institutional features of the labor market for teachers.

\footnotetext{
${ }^{9}$ The tax rate is taken by the education administrators as given. While it is plausible that the tax rate may be set by a different, fiscal, authority based on a political or normative decision process, we treat those as extraneous to our analysis. Thus the tax rates are considered exogenous in our model. We also do allow, but do not require, the tax rate to change exogenously over time. While this is not essential for our results, we explicitly allow for this possibility so as to (a) reflect the fluctuations in per student public education funding in relation to GDP growth seen in Table 1 and (b) make the results applicable to a further discussion in the paper of government policies which may indeed involve such rise in education funding.
} 
Specifically, as outlined in the Introduction, we distinguish between two alternative institutional regimes with respect to teacher compensation: the benchmark "merit pay regime", where teachers are paid competitive salaries (as are the production sector workers) according to their individual human capital attainments, and the "collective bargaining regime", the main focus of our analysis, where a uniform wage is set for all teachers by the union contract. In the next two sections we will derive the optimal education policy decisions under each regime marking where necessary the corresponding decision variables with superscripts ${ }^{\mathrm{MP}}$ and ${ }^{\mathrm{CB}}$, respectively. We will then define, under each regime, the economy's dynamic general equilibrium.

\section{The Benchmark Case: The Teacher Merit Pay Regime}

We assume throughout that an individual's human capital attainment is a universal measure of his capacity in any occupation, production or teaching, ${ }^{10}$ thus under the merit pay regime a college educated individual $\omega$ employed as a teacher will be paid the same salary of $\theta_{t} w h_{t}(\omega)$ he would get, if he chose the employment in the production economy, as given by the expression (3), i.e., his opportunity cost of working as a teacher. ${ }^{11}$ We assume for simplicity that given identical wages, an individual will always choose teaching over production occupation, based, for example, on hedonic preference which, however, plays only a marginal role and does not result in a wage differential.

The budget constraint on the aggregate teacher wage bill is thus given by

$$
\theta_{t} w \int_{\omega \in \Sigma_{t}^{M P}} h_{t}(\omega) d \mu_{t}(\omega)=T_{t}^{M P}
$$

where $T_{t}^{M P}$ is the tax revenue collected by the government in period $t$. Since all workers' wages under this regime are proportionate to their human capital levels, the tax revenue is given by

${ }^{10}$ We note that the empirical education literature also, understandably, treats education attainment as a proxy for teacher quality, due to the obvious difficulty to measure teaching ability directly.

${ }^{11}$ Since one's work career is summarily represented in our model by a single time period, we do not model the wage dynamics over the course of a worker's or teacher's career as he accumulates seniority and experience. The income variables in this framework therefore represent the aggregates of earnings over the entire career, such as the present values at a career's outset. 


$$
T_{t}^{M P}=\tau_{t} w\left(L_{t}+\theta_{t} H_{t}\right)
$$

where

$$
H_{t}=\int_{a_{t}^{*} \leq a(\omega) \leq A} h_{t}(\omega) d \mu_{t}(\omega)
$$

is the aggregate human capital of all college graduates working in the goods production and education sectors. We note that according to expression (7) the budget constraint (9) uniquely determines the aggregate quality of teachers

$$
q_{t}^{M P}=\int_{\omega \in \Sigma_{t}^{M P}} h_{t}(\omega) d \mu_{t}(\omega)=\frac{T_{t}^{M P}}{\theta_{t} w}
$$

Therefore, the objective of the maximum per student quality of basic education given by formula (8) is attained by maximizing the number of teachers $z_{t}^{M P}$ subject to keeping their aggregate quality as given by equation (11). This implies that the optimal stock of teachers is the bottom segment of college graduates, i.e., the optimal set $\Sigma_{t}^{M P}$ of teachers to be hired consists of all individuals whose levels of human capital $h_{t}(\omega)$ attained in college fall into the interval $\left[h\left(a_{t}^{*}\right), \bar{h}_{t}^{M P}\right]$ where $\bar{h}_{t}^{M P}$ is the human capital of the most able teacher hired under this scenario while $h\left(a_{t}^{* M P}\right)$ is the human capital attainment of the lowest ability college graduate in generation $G_{t}$, the cut-off ability level $a_{t}^{* M P}$ being defined by the expression (6). Therefore, the number of teachers to be hired is the measure of this set, $z_{t}^{M P}=\mu\left(\omega \mid h\left(a_{t}^{* M P}\right) \leq h_{t}(\omega) \leq \bar{h}_{t}^{M P}\right)$, while their aggregate absolute quality is given by the expression

$$
q_{t}^{M P}=\int_{h\left(a_{t}^{*}\right)}^{\bar{h}_{t}^{M P}} h_{t}(\omega) d \mu_{t}(\omega)
$$

Let $\bar{a}_{t}^{M P}$ denote the innate ability level which corresponds to the top teacher human capital $\bar{h}_{t}^{M P}$ as defined above. Then according to the production functions of basic and advanced education given by the expressions (6) and (7), we can write

$$
\bar{a}_{t}^{M P}=\frac{\bar{h}_{t}^{M P}+B h^{*}}{(b+B) C E_{t-1}^{M P}}
$$

and rewrite the expression (12) as 


$$
q_{t}^{M P}=\int_{a_{t}^{*} \leq a(\omega) \leq \bar{a}_{t}^{M P}} h_{t}(\omega) d \mu_{t}(\omega)
$$

Since innate ability was assumed to be uniformly distributed on $[0, A]$, the number of teachers to be hired can be expressed as

$$
z_{t}^{M P}=\frac{\bar{a}_{t}^{M P}-a_{t}^{* M P}}{A}
$$

Further in this section we will show that the education agency's optimization problem, which determines the optimal aggregate absolute quality of teachers $q_{t}^{M P}$ and their quantity $z_{t}^{M P}$, can be reduced to solving equation (11) in terms of $z_{t}^{M P}$. This according to (15) will set the optimal upper ability cut-off $\bar{a}_{t}^{M P}$, i.e., a characteristic of the relative teacher quality, which in turn according to (14) will determine the optimal aggregate teacher quality $q_{t}^{M P}$.

We can now summarize the fundamental elements of the model, under the benchmark teacher merit pay regime, and their relationships in a general equilibrium framework. We will first define the dynamic general equilibrium for given education agency's policy parameters under the merit pay regime and then incorporate the optimal education policy into the recursive dynamic general equilibrium framework.

Definition. Assuming the merit pay regime for teachers and given the initial per student basic education quality $E_{-1}^{M P}$ provided to generation $G_{0}$ individuals as children in period $t=0$, a sequence of tax rates $\left\{\tau_{t}\right\}_{t=0}^{\infty}$ and a sequence of education policy decisions, i.e., the numbers of teachers hired $\left\{z_{t}^{M P}\right\}_{t=0}^{\infty}$, which under this regime determine the set of teachers at the bottom of the human capital distribution of the respective generation's college graduates and thereby uniquely determine aggregate teacher quality levels $q_{t}^{M P}$, we define the dynamic general

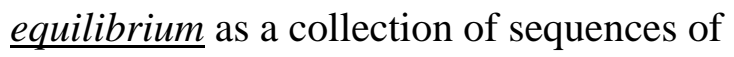

(a) the aggregate variables $\left\{Y_{t}, L_{t}, H_{t}^{y}, T_{t}^{M P}, E_{t}^{M P}, a_{t}^{* M P}\right\}_{t=0}^{\infty}$, i.e., respectively, the aggregate output, the inputs of unskilled and skilled human capital in production, the government's tax revenue, the quality of basic education provided to each student in period $t$, as well as the endogenous innate ability cut-off for college attendance in this period;

(b) the distributions of individual unskilled and skilled human capital attainment 
$\left\{l_{t}(\omega), h_{t}(\omega)\right\}_{t=0}^{\infty}$ resulting from the individual education decisions, as well as the employment decisions by all college graduates

such that

(i) each individual $\omega$ in generation $G_{t}$ upon receiving basic education of quality $E_{t-1}^{M P}$ makes a decision whether to go to college and if so whether to be employed as a teacher or in the production sector so as to maximize his income while taking as given teacher employment opportunities determined by the education agency's decisions, whereas his human capital level $l_{t}(\omega)$ or $h_{t}(\omega)$ (depending on his college attendance decision) is determined according to the education production functions (4) and (5). The quality of basic education $E_{t}^{M P}$ provided to the next generation $G_{t+1}$ individuals as children is determined by the expression (8) and the education policy variables $q_{t}^{M P}$ and $z_{t}^{M P}$.

(ii) the markets for skilled and unskilled labor in the production sector clear in each period:

$$
\begin{gathered}
L_{t}=\int_{0 \leq a(\omega) \leq a_{t}^{*}{ }^{M P}} l_{t}(\omega) d \mu_{t}(\omega), \\
H_{t}^{y}=\int_{\bar{a}_{t}^{M P} \leq a(\omega) \leq A} h_{t}(\omega) d \mu_{t}(\omega),
\end{gathered}
$$

where the ability cut-off for college attendance $a_{t}^{* M P}$ is determined by individual college attendance and employment decisions as defined in (i), which along with the education policy decision about the numbers of teachers $z_{t}^{M P}$ also determines the upper ability cut-off for teachers $\bar{a}_{t}^{M P}$; we note that the goods markets clear automatically in the present model; (iii) the aggregate tax revenue is composed of labor income taxes collected from all categories of employees, so the relationship (10) holds.

We can now define the education agency's optimal policy, for the teacher merit pay

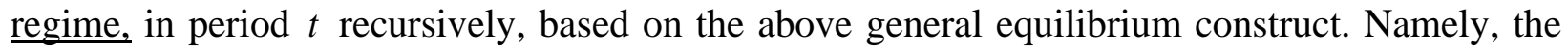
education agency chooses the upper ability cut-off $\bar{a}_{t}^{M P}$ for teachers in period $\mathrm{t}$ by solving the education quality maximization problem, which will also determine the number of teachers hired $z_{t}^{M P}$, while taking as given the aggregate tax revenue $T_{t}^{M P}$ and the distribution of skilled human capital attainment $h_{t}(\omega)$ by generation $G_{t}$ individuals. Noting the interdependence between the 
general equilibrium variables in period $t$ and the optimal education policy, we define the Education-Economy recursive dynamic equilibrium ( $R D E$ for brevity) as a fixed point of this relationship, recursively determined for each period $t$.

We will now proceed to reducing the education agency's optimization problem to an equation in terms of the optimal quantity of teachers $z_{t}^{M P}$. Using the relationships (4) and (5), and the assumption that ability is distributed uniformly on the interval $[0, A]$ we obtain

$$
\begin{aligned}
L_{t}^{M P} & =\int_{0 \leq a(\omega) \leq a_{t}^{* M P}} l_{t}^{M P}(\omega) d \mu_{t}(\omega)=C E_{t-1}^{M P} \int_{0}^{a_{t}^{* M P}} \frac{a}{A} d a=\frac{\left(a_{t}^{* M P}\right)^{2}}{2 A} C E_{t-1}^{M P} \\
H_{t}^{M P} & =\int_{a_{t}^{* M P} \leq a(\omega) \leq A} h_{t}^{M P}(\omega) d \mu_{t}(\omega)=\int_{a_{t}^{* M P}}^{A}\left[(b+B) C E_{t-1}^{M P} a-B h^{*}\right] \frac{1}{A} d a= \\
& =\frac{(b+B) C E_{t-1}^{M P}}{2 A}\left[A^{2}-\left(a_{t}^{* M P}\right)^{2}\right]-\frac{B h^{*}}{A}\left[A-a_{t}^{* M P}\right]
\end{aligned}
$$

Now substituting these expressions in the tax revenue formula (10) and using the expression (6) for $a_{t}^{* M P}$ we can transform the equation (11) into the following:

$$
q_{t}^{M P}=\frac{\tau_{t}(b+B) A C E_{t-1}^{M P}}{2} J_{t}^{M P}
$$

where

$$
J_{t}^{M P}=\left(1-\frac{2 B h^{*}}{(b+B) A C E_{t-1}^{M P}}+\frac{\theta_{t}\left(B h^{*}\right)^{2}}{\left(\theta_{t}(b+B)-1\right)(b+B)\left(A C E_{t-1}^{M P}\right)^{2}}\right)
$$

Similar to the derivation of the expression (17), we can rewrite the expression (14) as

$$
q_{t}^{M P}=\int_{a_{t}^{* M P}}^{\bar{a}_{t}^{M P}}\left[(b+B) C E_{t-1}^{M P} a-B h^{*}\right] A^{-1} d a=\frac{(b+B) C E_{t-1}^{M P}}{2 A}\left[\left(\bar{a}_{t}^{M P}\right)^{2}-\left(a_{t}^{* M P}\right)^{2}\right]-\frac{B h^{*}}{A}\left[\bar{a}_{t}^{M P}-a_{t}^{* M P}\right]
$$

Using the relationship (15) as well as (6), this can be rewritten as

$$
2 q_{t}^{M P}=\left(z_{t}^{M P}\right)^{2}(b+B) A C E_{t-1}^{M P}+z_{t}^{M P} \frac{2 B h^{*}}{\theta_{t}(b+B)-1}
$$

or equivalently, according to (18), as

$$
\left(z_{t}^{M P}\right)^{2}(b+B) A C E_{t-1}^{M P}+z_{t}^{M P} \frac{2 B h^{*}}{\theta_{t}(b+B)-1}-\tau_{t}(b+B) A C E_{t-1}^{M P} J_{t}^{M P}=0
$$


It is clear that the quadratic equation (21), in terms of $z_{t}^{M P}$, has a unique non-negative solution; thus according to the relationship (19) it uniquely defines $z_{t}^{M P}$ as a function of the prior period's education quality $E_{t-1}^{M P}$. The quantity of teachers $z_{t}^{M P}$ along with their quality $q_{t}^{M P}$ expressed by (20) will then determine the current period's quality of basic education $E_{t}^{M P}$ according to the formula (8). This completes an iteration of the recursion which uniquely defines the recursive dynamic equilibrium (RDE) in our model under the merit pay regime for teachers.

We have thus established the following result:

Proposition 1 (Existence and uniqueness of RDE in the merit pay regime). In each period $t=0,1, \ldots$, given the prior period's education quality $E_{t-1}^{M P}$ and college attendance decisions, the maximization of basic education quality (8) under the teacher merit pay regime has a unique solution for the optimal quantity and quality of teachers. This solution in turn uniquely determines for period $t$ basic education quality $E_{t}^{M P}$, and as a consequence the college attendance and employment decisions by generation $t$ individuals. This recursion defines the unique recursive dynamic equilibrium in the model under the teacher merit pay regime for all $t=0,1, \ldots$ given the initial generation's basic education quality $E_{-1}$.

\section{The Teacher Collective Bargaining Regime: Recursive Dynamic Equilibrium}

As discussed in the Introduction, we postulate that under the collective bargaining between the teachers' unions and the education agency all teachers in generation $G_{t}$ receive equal salary, which we denote by $I_{t}^{C B}$. Given the alternative occupation available to the college educated individuals in the production sector, the teacher salary figure $I_{t}^{C B}$ will uniquely determine the highest level of human capital attainment $\bar{h}_{t}^{C B}$ among the individuals who will choose to become teachers. Indeed, according to the expression (3) it should satisfy the equation ${ }^{12}$

$$
\theta_{t} w \bar{h}_{t}^{C B}=I_{t}^{C B}
$$

\footnotetext{
${ }^{12}$ While the teachers' union collective bargaining agreements stipulate wage differentials based on seniority, the income variables in this framework stand for the aggregates over one's career.
} 
Thus all the college graduates with human capital level $h_{t}(\omega)$ at or below $\bar{h}_{t}^{C B}$ will be obviously motivated to accept the employment as a teacher rather than to work in the production sector. However, the education agency's goal to maximize the overall education quality may dictate a minimum qualification requirement $\underline{h}_{t}^{C B}$ for the human capital of teachers, such that the optimal set $\Sigma_{t}^{C B}$ of teachers to be hired will consist of all individuals whose level of human capital $h_{t}(\omega)$ attained in college falls into the interval $\left[\underline{h}_{t}^{C B}, \bar{h}_{t}^{C B}\right]$. This implies that the number of teachers to be hired can be expressed as the measure of the above interval:

$$
z_{t}^{C B}=\mu\left(\omega \mid \underline{h}_{t}^{C B} \leq h_{t}(\omega) \leq \bar{h}_{t}^{C B}\right)
$$

Thus, according to (22) and (23), the agency's choice of teacher salary $I_{t}^{C B}$ (equivalently, the choice of the top human capital cut-off $\bar{h}_{t}^{C B}$ ) and the number of teachers $z_{t}^{C B}$ will jointly determine the lower teacher qualification cut-off $\underline{h}_{t}^{C B}$.

Recalling the production functions of basic and advanced education given, respectively, by the expressions (4) and (5), we define the cut-off innate ability levels $\underline{a}_{t}^{C B}$ and $\bar{a}_{t}^{C B}$ which characterize the teachers who possess, respectively, the cut-off levels of human capital $\underline{h}_{t}^{C B}$ and $\bar{h}_{t}^{C B}$ induced by the education agency's decisions described above. In other words (we again refer the reader to the glossary of notation available in Appendix 2),

$$
\underline{a}_{t}^{C B}=\frac{\underline{h}_{t}^{C B}+B h^{*}}{(b+B) C E_{t-1}} \quad \text { and } \quad \bar{a}_{t}^{C B}=\frac{\bar{h}_{t}^{C B}+B h^{*}}{(b+B) C E_{t-1}}
$$

Then the number of teachers to be hired, as defined by the formula (23), can be expressed as

$$
z_{t}^{C B}=\frac{\bar{a}_{t}^{C B}-\underline{a}_{t}^{C B}}{A}
$$

For the education authority's policy choice of $I_{t}^{C B}, z_{t}^{C B}$, to be feasible, the minimum teacher qualification threshold $\underline{h}_{t}^{C B}$ defined by (23) must belong to the range of human capital levels attained by college graduates. In other words, the corresponding ability level $\underline{a}_{t}^{C B}$ must exceed the college attendance cut-off level $a_{t}{ }^{*}$.

Thus according to (8) the basic education quality optimization problem can be stated as 


$$
\begin{aligned}
& \max _{z_{t}^{C B}, \bar{h}_{t}^{C B}} E_{t} \\
& \text { subject to (23), } \\
& z_{t}^{C B} \theta_{t} w \bar{h}_{t}^{C B}=T_{t}^{C B} \text { and } \\
& \underline{a}_{t} \geq a_{t}^{*}
\end{aligned}
$$

where $T_{t}^{C B}$ is the tax revenue collected by the government in period $t$.

Using the expressions (4), (5), (24), and (25), this problem can be restated in terms of the decision variables $z_{t}^{C B}$ and $\bar{a}_{t}^{C B}$, which will be helpful for providing a closed form solution to the problem. We place this technical analysis in Appendix 1.

Figure 1 below offers an illustration for the education quality optimization problem in period $t$.

Figure 1: Basic Education Optimization Problem under Collective Bargaining Regime

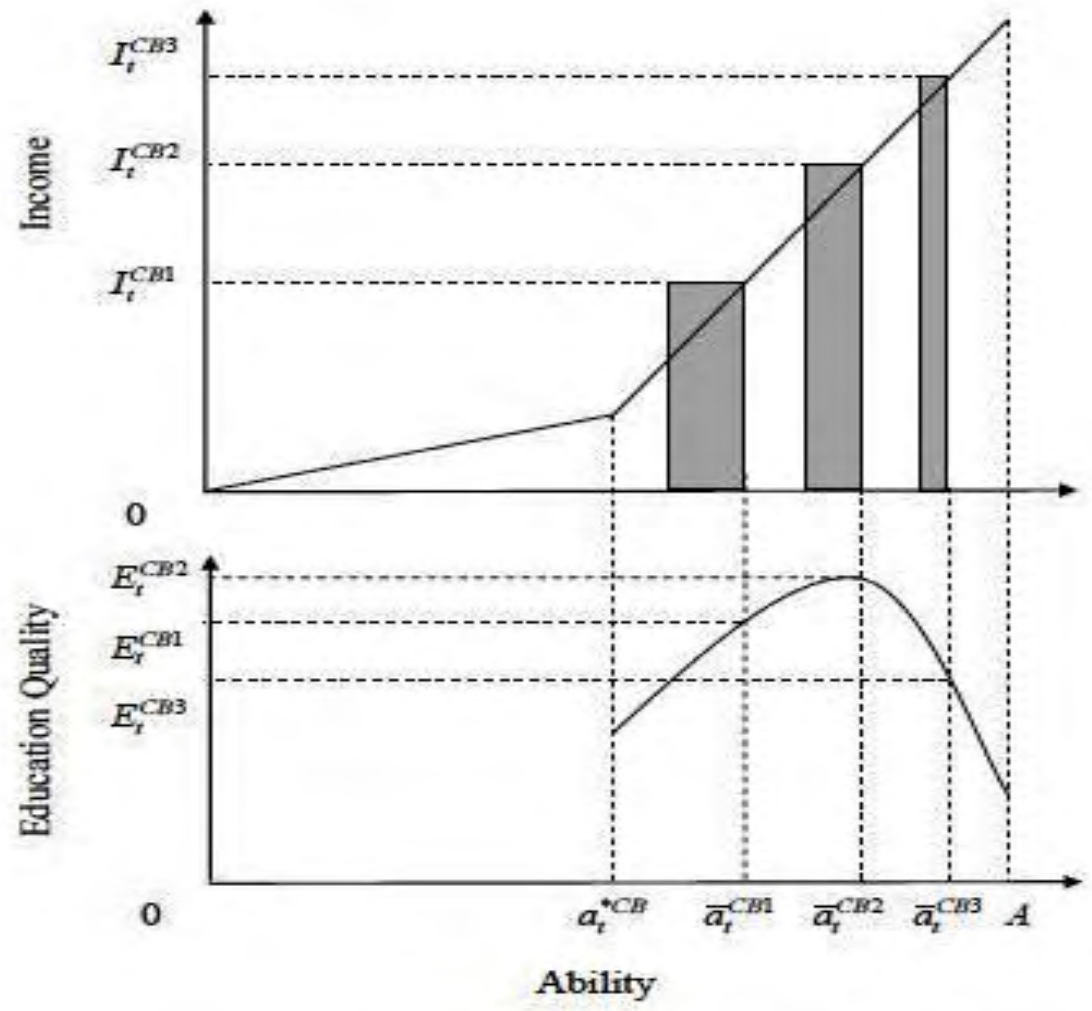

The horizontal axis represents workers' ability. In the top graph, the vertical axis represents the workers' wage incomes given by $w l_{t}$ for the unskilled workers and by $\theta_{t} w h_{t}$ for the skilled production sector workers with the corresponding human capital attainment. The 
sloped line in the top graph represents the distribution of incomes of production sector workers in generation $t$ as a function of individual ability according to the formulas (4) and (5), where the kink corresponds to the ability cut-off for college attendance $a_{t}^{*}$. The vertical bars illustrate several feasible education policy combinations of the number of teachers to be hired and teacher salaries satisfying the education budget constraint: $\left(z_{t}^{C B 1}, I_{t}^{C B 1}\right),\left(z_{t}^{C B 2}, I_{t}^{C B 2}\right),\left(z_{t}^{C B 3}, I_{t}^{C B 3}\right)$. The width of a bar corresponds to the number of teachers $z_{t}^{C B}$ while its height stands for teacher salary $I_{t}^{C B}$, so the bar's area is the total expenditure on basic education for the particular combination. Policy $\left(z_{t}^{C B 1}, I_{t}^{C B 1}\right)$ represented by the left-most bar in the figure is characterized by the lowest student-teacher ratio (the largest quantity of teachers) but also the lowest teacher quality. This policy option is highly inefficient in terms of education quality derived from the given budget revenue, as shown by the large deadweight loss represented by the triangular portion of the bar located above the sloped line: this is the excess salary paid to teachers above their opportunity cost value. The deadweight loss is the highest here because this policy involves hiring an inefficiently large number of low quality teachers who nevertheless have to be paid at the same rate as their best peer. The policy $\left(z_{t}^{C B 3}, I_{t}^{C B 3}\right)$ (the right-most bar in the figure) delivers the highest teacher quality, relative to the other two policy combinations. This education policy has the lowest deadweight loss associated with the collective bargaining regime but it still has low per pupil education quality due to small number of teachers, i.e., high student-teacher ratio. The interior policy option $\left(z_{t}^{C B 2}, I_{t}^{C B 2}\right)$ is where the per student education quality $E_{t}$ is the highest among the three options depicted, providing the balance in terms of student-teacher ratio and the deadweight loss. This fact is illustrated by the graph at the bottom of the figure, where the vertical axis measures the values of $E_{t}$ corresponding to different policy combinations uniquely identified by the ability of the top teacher under the policy.

We define the dynamic general equilibrium under the teachers' collective bargaining regime for given education policy decisions similarly to the benchmark merit pay regime, except that here the education policy decisions include the uniform teacher salaries $I_{t}^{C B}$ set for in each period, which individuals take as given in their education and employment decisions. 
Accordingly, in lieu of the expression (10), the aggregate tax revenue composed of labor income taxes collected from all categories of employees is given in this case by

$$
T_{t}^{C B}=\tau_{t}\left(w_{t} L_{t}+\theta_{t} w_{t} H_{t}^{y}+z_{t}^{C B} I_{t}^{C B}\right)
$$

where $H_{t}^{y}$ stands, as before, for the aggregate human capital of the college educated workers in the production sector.

Likewise, we recursively define the optimal education policy in period $t$ based on the above general equilibrium construct. Namely, the education agency chooses teacher salaries $I_{t}^{C B}$ and the number of teachers $z_{t}^{C B}$ for period $t$ by solving the optimization problem (26) where the top teacher quality $\bar{h}_{t}^{C B}$ is determined by equation (22), while taking as given the economy's general equilibrium values of the aggregate tax revenue $T_{t}^{C B}$ and the distribution of skilled human capital attainment $h_{t}^{C B}(\omega)$ by generation $G_{t}$ individuals. Similar to the benchmark case, this leads to the Education-Economy recursive dynamic equilibrium (RDE) construct.

Since the premise of this theoretical analysis is to capture the effect of economic growth on the dynamics of the educational resources, the quantity and quality of teachers, we will now impose some conditions on parameters of basic and college education systems, the level of education tax rates, skill premium in the production sector, as well as on per student basic education quality $E_{-1}^{C B}$ provided to students in the initial generation $G_{0}$, such as to ensure economic growth.

Assumption 2 Education funding is sufficiently high and both basic and college education technologies are sufficiently productive to make sustained growth of human capital possible. Specifically, $v \geq 1$ (returns to the human capital of teachers are non-decreasing) ${ }^{13}$ and the productivity coefficients $C$ and $(b+B)$ are sufficiently large, while education tax rates $\tau_{t}$ are not too low while not exceeding $1-\frac{\gamma}{2 v}$ at all times.

\footnotetext{
${ }^{13}$ The specific technical role of the non-decreasing returns requirement is to ensure growth of basic education quality with a sustained growth factor $g>1$ stated in Lemma 1 below. In the case of $v<1$, Lemma 1 and ensuing main results of the paper will remain qualitatively correct in transition to a steady state if the initial stocks of human capital in the economy are low.
} 
The gist of all of the parameter restrictions imposed by Assumption 2 is ensuring that the funding, determined by the tax rates, and productivity of both basic and college level education systems, determined by respective parameters $C$ and $(b+B)$ of the education production functions (4) and (5) under the condition of non-decreasing returns to teacher quality $v \geq 1$ discussed in Section 2.4, are sufficient to make sustained growth of human capital attainments across generations possible. The fact that such sustained growth of education quality, particularly at the basic level, actually takes place under these conditions is established in Lemma 1 below. The additional condition $\tau_{t} \leq 1-\frac{\gamma}{2 v}$ in Assumption 2 will be certainly met if $v \geq \gamma$, i.e. if the relative importance of teacher quality in schooling effectiveness is not lower than that of the teacher-student ratio, which will clearly be the case here under the natural requirement that $\gamma \leq 1$, i.e. that the there are non-increasing returns to the number of teachers.

More specific technical restrictions on the parameters involved in Assumption 2 are spelled out in Appendix 1 where we then prove the existence and uniqueness of the recursive dynamic equilibrium (RDE) in the model under the teacher collective bargaining regime, which is somewhat more involved than a similar result in Proposition 1 for the benchmark merit pay case. We do so by also deriving the explicit solution of the optimal education policy problem (26) in terms of decision variables $z_{t}^{C B}$ and $\bar{a}_{t}^{C B}$, as well as the optimal lower ability cut-off among those hired as teachers $\underline{a}_{t}^{C B}$ and the resulting recursive dynamic equilibrium sequence of these variables. Specifically, we prove the following

Proposition 2 (RDE solutions under the teachers' collective bargaining regime).

(i) In each period $t=0,1, \ldots$, given the prior period's education quality $E_{t-1}^{C B}$ and individual college attendance decisions, the basic education quality optimization problem (26) with the basic education budget $T_{t}^{C B}$ defined by the relationship (27), has a unique solution characterized by the following expressions, respectively, for the optimal quantity and the absolute quality (i.e. the aggregate human capital) of teachers

$$
z_{t}^{C B}=\left(\left(\frac{\gamma}{2 v+\gamma}\right)\left(\frac{\tau_{t}}{1-\tau_{t}}\right)\right)^{1 / 2}\left(J_{t}^{C B}\right)^{1 / 2}, \quad q_{t}^{C B}=\frac{v \tau_{t}(b+B) A C E_{t-1}^{C B}}{2 v+\gamma} J_{t}^{C B}
$$

where 


$$
J_{t}^{C B}=\left(1-\frac{2 B h^{*}}{(b+B) A C E_{t-1}^{C B}}+\frac{\theta_{t}\left(B h^{*}\right)^{2}}{\left(\theta_{t}(b+B)-1\right)(b+B)\left(A C E_{t-1}^{C B}\right)^{2}}\right),
$$

as well as the upper and lower ability cut-offs for teachers to be hired:

$$
\bar{a}_{t}^{C B}=\frac{B h^{*}}{(b+B) C E_{t-1}^{C B}}+A z_{t}^{C B}\left(\frac{v\left(1-\tau_{t}\right)}{\gamma}+\frac{1}{2}\right), \quad \underline{a}_{t}^{C B}=\frac{B h^{*}}{(b+B) C E_{t-1}^{C B}}+A z_{t}^{C B}\left(\frac{v\left(1-\tau_{t}\right)}{\gamma}-\frac{1}{2}\right)
$$

(ii) This optimal solution for period $t$ education policy uniquely determines period $t$ basic education quality $E_{t}^{C B}$ and as a consequence, the college attendance decisions by generation $t$ individuals. This recursion defines the unique recursive dynamic equilibrium in the model under the teachers' collective bargaining regime for all $t=0,1, \ldots$ given the initial generation's basic education quality $E_{-1}$.

\section{The Dynamics of the Quantity and Quality of Teachers under Collective Bargaining}

In this section we will establish the main dynamics results for the teachers' collective bargaining regime, which is the main focus of our analysis. In Section 6, we will turn to the dynamics under the benchmark merit pay regime and will then characterize and discuss the comparison between the two.

The following important auxiliary facts concerning the dynamics under the collective bargaining regime are proven in Appendix 1:

Lemma 1 (Growth of Basic Education Quality). The recursive equilibrium dynamics under the collective bargaining regime for teachers exhibits sustained growth of the quality of per student basic education. Specifically, there is a factor $g>1$ such that $E_{t}^{C B}>g E_{t-1}^{C B}$ for all $t=0,1, \ldots$

Lemma 2 (The Interiority Property under the Collective Bargaining). In the recursive dynamic equilibrium, the ability of the least qualified teacher exceeds the college attendance cut-off ability in all time periods, i.e. $\underline{a}_{t}^{C B}>a_{t}^{*}$ is true for $t=0,1, \ldots$ Thereby the human capital of the least qualified teacher will not be the lowest among his contemporary college graduates.

Lemma 3 The ability cut-off for college attendance $a_{t}^{*}$ satisfies equality (6), i.e., 


$$
a_{t}^{*}=\frac{1}{C E_{t-1}^{C B}} \frac{\theta_{t} B h^{*}}{\theta_{t}(b+B)-1}
$$

which means that an individual will choose to attend college if and only if his resulting skilled human capital given by formula (5) adjusted for the net productivity augmentation $\theta_{t}$ will exceed his unskilled human capital derived from the basic stage of education according to its production function (4).

Remark. Since we assumed that individuals make a decision whether to attend college solely on the basis of the income motive, it is clear that the ability cut-off for college attendance $a_{t}^{*}$ should satisfy the inequality

$$
a_{t}^{* C B} \leq \frac{1}{C E_{t-1}^{C B}} \frac{\theta_{t} B h^{*}}{\theta_{t}(b+B)-1}
$$

Indeed, according to (4), (5) and (2), (3), an individual with ability exceeding the right hand side of (31) will certainly increase his income by going to college. Lemma 3 demonstrates that inequality (31) is in fact satisfied as equality in equilibrium. The reason this fact is less than obvious under collective bargaining for teachers (while straightforward in the merit pay regime) is that as a result some individuals get paid above their production sector opportunity cost, hence a potential distortion in the cost-benefit analysis of the college attendance decision.

The result of Lemma 1 provides for an underlying endogenous growth feature of our model where the rise of the human capital attainments at the basic level is the "engine of growth". The following result, which characterizes the evolution of income inequality in our model, shows that the growth in overall human attainments is disproportionately higher at the higher end of the ability distribution. This fact, which we term "the rising talent premium", will provide helpful insight into the mechanism behind the main results of this paper.

Proposition 3 (The Rising Talent Premium). The recursive equilibrium dynamics exhibits growing inequality within the group of skilled individuals, as well as the rise in inequality between this group and the unskilled.

The proof, placed in Appendix 1, applies both to the collective bargaining and merit pay cases. It also derives the following expression for the income disparity within the skilled labor 
cohort given by the ratio of incomes of the top to bottom earners of generation $G_{t}$ college graduates:

$$
\sigma_{t}^{s}=\frac{\theta_{t}(b+B)}{a_{t}^{*}}\left(A-\frac{B h^{*}}{C E_{t-1}}\right)
$$

which shows that the rise of income inequality among skilled workers can be attributed to (i) the rising basic education quality $E_{t-1}$, according to Lemma 1, which increases human capital and income of all workers, but disproportionately more so at the high end of the ability distribution, as well as

(ii) the falling college attendance ability cut-off $a_{t}^{*}$, according to Lemma 2, which brings lower ability workers into the fold of the skilled, thereby further increasing the intra-group inequality.

We now turn to our main focus on the dynamics of teacher quantity and quality which accompanies and is entailed in the process of growth. The following Lemma proven in Appendix 1 addresses a step in this recursion: it characterizes the effect of rising basic education quality $E_{t-1}^{C B}$ in period $t-1$ on education decision variables in period $t$.

Lemma 4. The effects of increased quality of basic education $E_{t-1}^{C B}$ in period $t-1$ are expanded college attendance (lower college attendance ability cut-off) in the next generation, larger quantity of teachers, and their lower quality given by their lower ability cut-off values. Specifically, the following is true for all $t=0,1, \ldots$ in the recursive dynamic equilibrium:

$$
\frac{\partial a_{t}^{*}}{\partial E_{t-1}^{C B}}<0, \quad \frac{\partial z_{t}^{C B}}{\partial E_{t-1}^{C B}}>0, \quad \frac{\partial \bar{a}_{t}^{C B}}{\partial E_{t-1}^{C B}}<0, \quad \frac{\partial \underline{a}_{t}^{C B}}{\partial E_{t-1}^{C B}}<0
$$

Combining the last two facts, $\frac{\partial \bar{a}_{t}^{C B}}{\partial E_{t-1}^{C B}}<0, \frac{\partial \underline{a}_{t}^{C B}}{\partial E_{t-1}^{C B}}<0$ for $t=0,1, \ldots$, with Lemma 1, which shows that education quality $E_{t-1}^{C B}$ does in fact grow over time, yields one of our central results.

Theorem 1 (Dynamics of the Quantity and Quality of Teachers under Collective Bargaining). The recursive dynamic equilibrium (RDE) exhibits the following evolution of education policy variables:

- the quantity of teachers $z_{t}^{C B}$ grows over time; 
- the relative quality of teachers characterized by the range of their innate abilities falls: both the upper and the lower cut-offs $\bar{a}_{t}^{C B}, \underline{a}_{t}^{C B}$ decrease over time;

- the college attendance ability cut-off $a_{t}^{*}$ also drops over time (thus the college-bound population expands); $a_{t}^{*}$ remains consistently below the lower ability cut-off for teachers $\underline{a}_{t}^{C B}$ (according to Lemma 2).

The decline of the relative quality of teachers measured against the contemporaneous college educated cohort does not imply the fall in their absolute levels of human capital. As shown by the following fact proven in Appendix 1 the absolute human capital levels of teachers will, in fact, grow. This is due to the overall growth in education established in Lemma 1, which permits relatively less-able teachers in the new generations to attain higher human capital level than did relatively more able teachers of previous generations.

Corollary. While the relative quality of teachers falls over time in the RDE under the collective bargaining regime (according to Theorem 1), the absolute quality of teachers characterized by their human capital attainment grows: both the human capital of the top teacher and the least qualified one, $\bar{h}_{t}^{C B}, \underline{h}_{t}^{C B}$, rise over time.

Discussion. The intuition for the above results derives from the mechanics of economic growth in our model. Rising per student quality of basic education (Lemma 1) opens up the opportunity to pursue higher education for an expanding group of students. Namely, college attendance becomes worthwhile for an ever broader population, adding on students with relatively low ability. At the same time, the human capital attainment of highly able students increases disproportionately relative to their less able peers due to increasing returns to ability exhibited by the college education production function (5). Thus economic growth drives the rise of income inequality within the group of college graduates, as was spelled out in Proposition 3 above. As a result, the opportunity cost of highly able college graduates measured by their increasing relative earnings in the production sector rises over time. Therefore hiring high ability individuals as teachers is becoming a relatively more expensive option (we have characterized this as an effect of the rising talent premium), which pushes the quality-quantity trade-off for the education 
policy-makers in favor of the latter. In other words, hiring a larger number of teachers of relatively lower quality is becoming an increasingly more cost-effective policy. ${ }^{14}$

Figure 2 below illustrates the evolution of the optimal education policy choices and the corresponding per-student education quality levels, along with the evolution of income distribution in successive time periods, $t$ and $t+1$.

Figure 2: Basic Education Optimization Problem in Period $t$ and $t+1$ under Collective Bargaining Regime

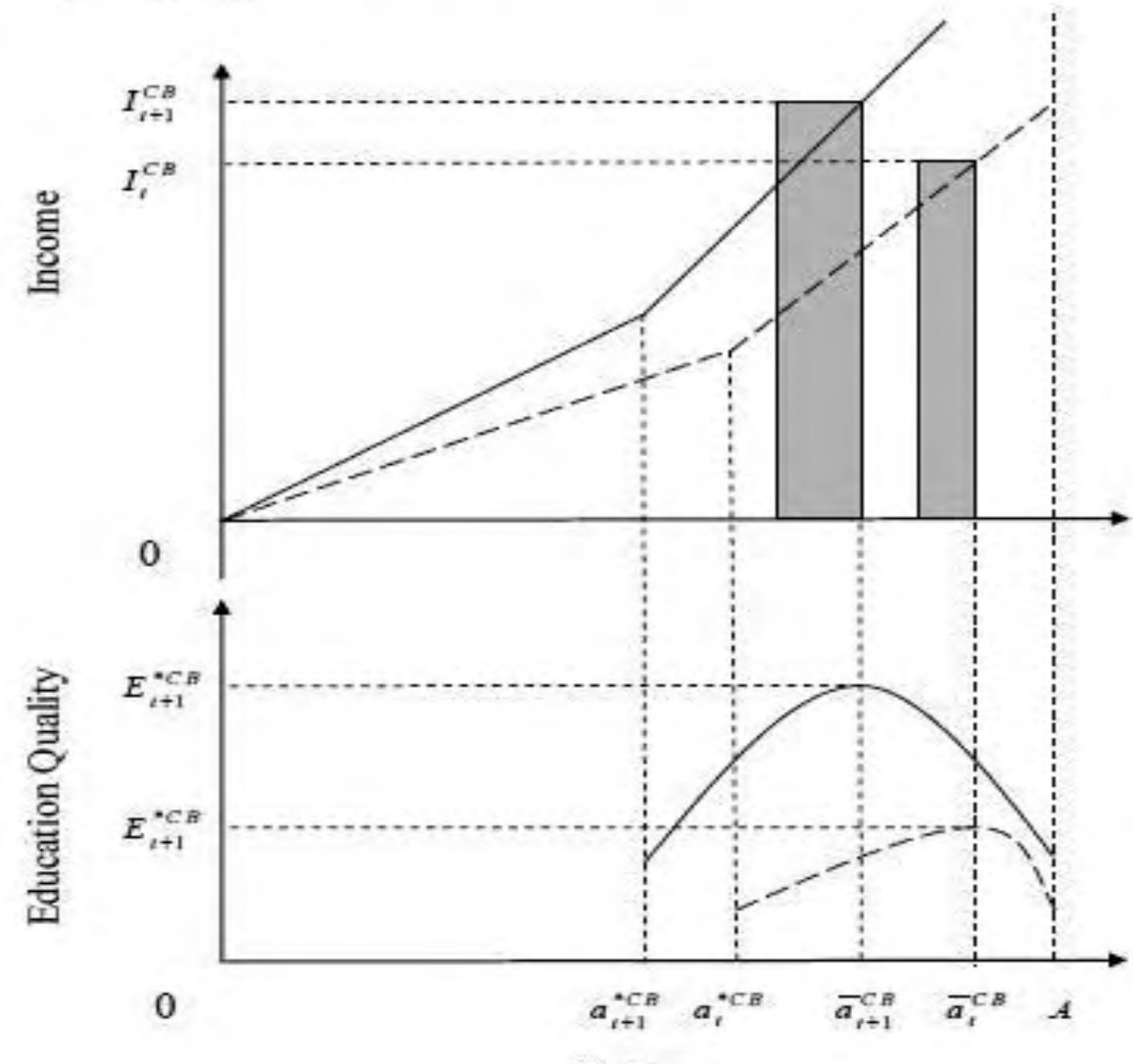

Ability

The parts of the graph pertaining to period $t$ correspond to the illustrations given in Figure 1 of Section 4: the dashed sloped line in the top graph represents the income distribution

\footnotetext{
${ }^{14}$ The effect of rising opportunity cost of teaching is particularly strong among college educated women, as documented by Lakdawalla (2006) among others, due to expanding non-teaching job market opportunities for women. This fact can be captured in our model, for example, by introducing a gender wage gap in non-teaching occupations. As the gap exogenously declines over time, the opportunity cost of teaching increases especially fast for women, which adds impetus to the trend in favor of hiring larger quantity of lower quality teachers described above.
} 
of production sector workers in period $t$, while the right bar depicts the optimal education policy (the bar's width $z_{t}$ is the number of teachers; its height is teacher salary in period $t$ ); the dashed parabola in the bottom graph tracks per student education quality in period $t$ corresponding to education policy options similar to Figure 1. The solid sloped line in the top graph represents income distribution in period $t+1$. It exhibits a kink further to the left, i.e., a lower college attendance ability cut-off than in period $t$, consistent with Theorem 1. Furthermore, the comparison of the solid and dashed lines illustrates the fact expressed by Proposition 3 that the benefit derived by skilled individuals from the quality of basic education grows disproportionately with their ability. This implies the rising relative cost of highly able teachers and results in the shift of the quantity-quality trade-off depicted by the position of the bar corresponding to the optimal education policy choice in period $t+1$ to the left of the bar corresponding to period $t$, as stated in Theorem 1. The position of the solid parabola relative to the dashed one reflects lower optimal relative quality of teachers in period $t+1$, consistent with Theorem 1, and higher per student education quality than in the previous period, as per Lemma 1.

Much of the recent growth literature which presents the evidence of increasing dispersion of incomes of skilled workers over the last four decades of the XX century attributes this to the skill biased nature of technological change (see, e.g., Acemoglu, 1998, 2002 and Galor and Moav, 2000). A competing view, supported, e.g., by the findings of Eckstein and Nagypal (2004), gives more credence to the evidence of increasing dispersion in educational attainments. This view is consistent with our Proposition 3 where the rising income inequality was derived exclusively from the growing provision of basic education, which has unequal impact on individuals across the distribution of abilities because of the complementary relationship between individual ability and quality of education, ${ }^{15}$ hence the rising talent premium effect. Thus in our model the rising inequality remains in effect even when skill premium coefficients

\footnotetext{
${ }^{15}$ A somewhat similar argument for the magnifying effect that greater public education funding may have on income inequality is advanced by Glomm and Kaganovich (2003) in the presence of complementarity between public and parental private inputs, imperfect altruism, and borrowing constraints. The fact of such complementary relationship and its implications for inequality was documented for the case of Britain by LeGrand (1982).
} 
$\theta_{t}$ are held constant over time. Of course one should expect that a rise in skill premium $\theta_{t}$ will further exacerbate the expansion in income inequality. We will next verify this conjecture, that there is an additional SBTC effect on the cost of talent and thereby on the optimal quality and quantity of teachers, distinct from the rising talent premium effect.

We will now introduce the exogenous skill biased technological change into the model given by positive shocks to the skill premium coefficients $\theta_{t}$, and will explore its effects on the education policy variables and the quality of education. Specifically, we consider the recursive dynamic equilibrium (RDE) corresponding to the original exogenously given sequence $\left\{\theta_{t}\right\}_{t=o}^{\infty}$ (the benchmark sequence, which may, in particular, be stationary) and assume that the productivity augmentation of skilled labor receives a positive shock from time $t_{0}$ on, i.e. that for $t=t_{0}, t_{1}, \ldots$ the values $\theta_{t}$ are replaced with some $\theta_{t}^{\prime}>\theta_{t}$. We will characterize the effect of this exogenous change on the RDE, particularly on the education policy variables. We obtain the following comparative dynamics result (see Appendix 1 for the proof).

Theorem 2 (The Effect of Skill Biased Technological Change). Consider the comparative dynamics experiment described above, where skill premium coefficients $\theta_{t}$ receive an exogenous positive shock from period $t_{0}$ on. The corresponding recursive dynamic equilibrium, relative to the original $R D E$, will be characterized, for $t \geq t_{0}$ by

- lower quantity of teachers $z_{t}^{C B}$;

- lower aggregate quality of teachers $q_{t}^{C B}$ and therefore

- lower quality of basic education $E_{t}$.

Note the negative effect on both the number and aggregate quality of teachers which is due to an upward shock to the cost of skilled labor. The Theorem thus shows that the technological change biased toward skilled labor will have a detrimental (SBTC) effect on the absolute quality of basic education, exacerbating the negative rising talent premium effect of a secular downward trend in the relative quality of teachers stated in Theorem 1 . These results will apply, in particular, when education tax rate $\tau$ stays constant, which means that education 
budget grows at the rate of GDP growth.

This leads to an important implication of our analysis: given the negative impact of rising skill premium on the quality of education, a policy aimed at neutralizing this effect would require an increase in funding of education (assuming no change in the institutional setup of the school system and teachers' labor market) at a rate faster than GDP growth, i.e. raising the fraction of GDP devoted to education. Note that Rangazas (2002), in his accounting of sustained growth of the U.S. economy since 1870, while attributing its biggest share to human capital accumulation, distinguishes between an unsustainable ("transitional") component due to the rise of education expenditures as a share of GDP, and the sustainable one caused by their balanced growth proportionately to that of GDP, as well as the other two "sustainable" factors: intergenerational human capital externality and a secular trend of technological change. Our results, however, suggest that these factors are intertwined. Indeed, the rising "talent premium" and technological progress lead to increasing relative cost of maintaining a given teacher quality standard, thereby if a steady growth of human capital were to be sustained, educational expenditures would have to rise faster than GDP. While this may call into question the separation between the "transitional" and "sustainable" factors in human capital accumulation, the distinction is limited to the current education technology, which is itself plausibly undergoing transition to a new paradigm.

\section{Dynamics under the Merit Pay Regime: Comparative Results}

The uniform pay requirement for teachers imposed by the collective bargaining obviously ensures that most teachers are paid above their marginal product. This clearly creates inefficiency in the allocation of funding of basic education. Therefore one can expect that in the absence of the distortion, under the merit pay regime, a higher quality of basic education could be produced given the same fundamentals at the outset. We will indeed first of all establish such static and dynamic comparisons and will also provide a comparative characterization of the allocation of educational resources in terms of the quantity and quality of teachers under the two regimes. Specifically, we establish the following fact (see its proof in Appendix 1):

Theorem 3. Compare the dynamics of educational and economic outcomes of the two economies starting from the same initial per student basic education quality $E_{-1}$ provided to generation $G_{0}$ at $t=0$ and given the same sequence of tax rates $\left\{\tau_{t}\right\}_{t=0}^{\infty}$, whose only difference is the teacher 
pay arrangement: one with collective bargaining resulting in the uniform teacher wage, and the other with merit pay for teachers. Then

(i) the merit pay arrangement yields relatively higher quality of basic education at all times, i.e., $E_{t}^{M P}>E_{t}^{C B}$ is true at $t=0,1, \ldots$;

(ii) the higher quality of basic education under the merit pay regime is attained through the allocation of educational resources characterized by the higher quantity of teachers as well as their higher absolute quality (i.e., their aggregate human capital) under the merit pay regime, i.e., the inequalities $z_{t}^{M P}>z_{t}^{C B}$ and $q_{t}^{M P}>q_{t}^{C B}$ are true at $t=0,1, \ldots$;

(iii) the relative quality at the top of teacher pool is also higher under the merit pay regime subject to an additional condition that the contribution (the elasticity in the basic education production function (8)) $\gamma$ of the teacher-student ratio is not too small relative to that of the teacher quality given by parameter $v$. Specifically, under the condition that $\frac{\gamma}{2 v} \geq \frac{\left(1-\tau_{t}\right)}{1+2 \sqrt{1-\tau_{t}}}$ the inequality $\quad \bar{a}_{t}^{M P}>\bar{a}_{t}^{C B}$ is true at $t=0,1, \ldots$

\section{Remarks.}

1. The parametric condition imposed in part (iii) of the Theorem can be best understood when combined with the conditions $v \geq 1$ and $\frac{\gamma}{2 v} \leq 1-\tau_{t}$ imposed by Assumption 2 in the previous section. While the latter imposes a natural upper bound on the relative contribution of teacherstudent ratio (see the discussion following Assumption 2), the new condition sets a plausible lower bound on it, consistent with the upper one.

2. The basic education quality dominance result in part (i), when applied to formula (6), implies that the college-attendance ability cut-off $a_{t}^{*}$ will be always relatively lower under the teachers' merit pay regime. Combined with the result of Lemma 2, the interiority of the teacher cohort under the collective bargaining regime, this means that the relative quality at the bottom of the distribution of teachers will always be inferior to that under the collective bargaining. Coupled with the part (iii) result, and consistent with the fact $z_{t}^{M P}>z_{t}^{C B}$ in part (ii), this offers a compelling and realistic comparison of the distributions of teacher quality across the regimes: the merit pay arrangement is characterized by a strictly broader range of teacher quality along with 
smaller average class size, resulting in the overall higher per student education quality.

3. The result similar to that of Theorem 2 on the negative effect of skill biased technological change on the quantity and quality of teachers and on the quality of basic education is also true in the merit pay case. We state this here without proof, which can be obtained along the lines of the proof of Theorem 3 using the expressions (11) and (20).

Finally, we obtain the following characterizations, also proven in Appendix 1, of the dynamics of educational variables under the merit pay regime analogous to those established in Theorem 1 for the collective bargaining regime.

Theorem 4 (Dynamics of the Quantity and Quality of Teachers under Merit Pay). The recursive dynamic equilibrium (RDE) exhibits the following evolution of inputs in basic education:

- the quantity $z_{t}^{M P}$ of teachers grows over time, so do the absolute aggregate quality of teachers $q_{t}^{M P}$, as well as the quality of basic education $E_{t}^{M P}$;

- the relative quality of teachers characterized by the range of their innate abilities falls: both the upper and the lower cut-offs $\bar{a}_{t}^{M P}, a_{t}^{{ }^{* M P}}$ decrease over time.

Theorem 4 shows that the phenomenon of the quantity-quality trade-off in the dynamics of teacher staffing is also in effect under the merit pay regime. This is indeed due to the same factor, the rising talent premium (see in the discussion following Theorem 1) which is at work under either of the teacher pay regimes. However, according to part (iii) of Theorem 3, the quantity-quality trade-off in the merit pay case is characterized by a less significant relative quality decline (and stronger absolute quality gains, as per part (ii) of Theorem 3) than occurring under collective bargaining. More precisely, the collective bargaining regime exacerbates the teacher quantity-quality trade-off, particularly in terms of the loss of the most able teachers.

Thus, the combination of our main results obtained in Theorems 1-4 offers a taxonomy of factors contributing to the dynamics of quantity-quality trade-off in teacher staffing: (i) human capital attainments rise over time, disproportionately so for highly able individuals ("the rising talent premium"), which leads to increasing opportunity cost of teaching for such individuals and pushes the trade-off in favor of quantity under both teacher pay regimes according to Theorems 1 and 4; (ii) Theorem 3 shows that the wage compression under the collective bargaining regime 
exacerbates the loss in teacher quality; (iii) the rise of skill premium, resulting from technological change, is an additional, independent factor, which strengthens the quantity-quality trade-off in favor of the former, according to Theorem 2.

\section{Conclusions}

Over the last forty years, education policy in the U.S. has changed significantly, focusing in particular on lowering the student-teacher ratio. We have developed a model which offers an insight into this evolution by relating it to the changes in the US economy characterized by rising skill premium and overall income inequality. Our model predicts that as incomes of college educated individuals rise and become more dispersed (the phenomenon we call the "rising talent premium"), education policy-makers are forced to adjust relative teacher salaries and thereby the quality standards. Education quality is optimized by lowering relative quality of teachers while increasing their numbers. This causes the higher ability college graduates to choose private sector employment which offers higher reward to skilled workers. We show moreover that this loss of the more talented workers by the teaching profession is exacerbated by the teacher wage compression resulting from the teacher union imposed collective bargaining agreements.

Further, we argue that a rise in skill premium caused, in particular, by skill biased technological change will deepen the negative trends in the relative quality of education. Indeed, the labor of college graduates will further appreciate relative to the average wage and hence relative to the tax revenue. Countering this trend would therefore require an increase in the share of GDP spent on basic education, assuming that the institutional setup of the school system remains unchanged.

Our finding that skill biased technological change can have a negative effect on the quality of education is an interesting case of negative feedback, since SBTC literature points to the rise in the supply of skill due to growing availability of education as its underlying cause. Furthermore, this leads to an issue which appears important for future research on the aggregate long term effects of SBTC: as technical change brings about productivity gains, one needs to factor in its effects on the cost and quality of education and the corresponding policy responses in order to assess the full long-term impact. 


\section{References}

Aaronson, D., L. Barrow, and W. Sander, 2007. Teachers and Student Achievement in the Chicago Public High Schools. Journal of Labor Economics 25, 95-135.

Acemoglu, D., 1998. Why Do New Technologies Complement Skills? Directed Technical Change and Wage Inequality. Quarterly Journal of Economics 113, 1055-1089.

Acemoglu, D., 2002. Technical Change, Inequality, and the Labor Market. Journal of Economic Literature 40, 7-72.

Angrist, J. and V. Lavy, 1999. Using Maimonides' Rule To Estimate The Effect Of Class Size On Scholastic Achievement. Quarterly Journal of Economics 114, 533-575.

Bacolod, M., 2007. Do Alternative Opportunities Matter? The Role of Female Labor Markets in the Decline of Teacher Quality. Review of Economics and Statistics 89:737-751.

Ben-Porath, Y., 1967. The Production of Human Capital and the Life-Cycle Earnings. Journal of Political Economy 75, 352-365.

Betts, J., 1998. The Impact of Educational Standards on the Level and Distribution of Earnings. American Economic Review 88, 266-275.

Card, D. and A. Krueger, 1992. Does School Quality Matter? Returns to Education and the Characteristics of Public Schools in the United States. Journal of Political Economy 100, 140.

Clotfelter, C., H. Ladd, and J. Vigdor, 2007. How and Why Do Teacher Credentials Matter for Student Achievement? NBER Working Paper No. W12828.

Corcoran, S., W. Evans, and R. Schwab, 2004. Changing Labor-Market Opportunities for Women and the Quality of Teachers, 1957-2000. American Economic Review Papers and Proceedings 94, 230-235.

Cunha, F. and J. Heckman, 2007. The Technology of Skill Formation. American Economic Review Papers and Proceedings 97, 31-47.

Digest of Education Statistics, 2007. U.S. Department of Education, National Center for Education Statistics, NCES 2008-022. http://nces.ed.gov/pubs2008/2008022.pdf

Eckstein, Z.. and E. Nagypal, 2004. The Evolution of U.S. Earnings Inequality: 1961-2002. Federal Reserve Bank of Minneapolis Quarterly Review 28 (2), 10-29.

Eckstein, Z. and I. Zilcha, 1994. The Effects of Compulsory Schooling on Growth, Income Distribution and Welfare. Journal of Public Economics 54, 339-359.

Flyer, F. and S. Rosen, 1997. The New Economics of Teachers and Education. Journal of Labor Economics 15, S104-S139.

Galor, O. and O. Moav, 2000. Ability-Biased Technological Transition, Wage Inequality, and Economic Growth. Quarterly Journal of Economics 115, 469-497.

Galor, O. and J. Zeira, 1993. Income Distribution and Macroeconomics. Review of Economic Studies 60, 35-52.

Gilpin, G., and M. Kaganovich, 2009. The Quantity and Quality of Teachers: A Dynamic Tradeoff. CESifo Working Paper Series No. 2516. 
Glomm, G. and M. Kaganovich, 2003. Distributional Effects of Public Education in an Economy with Public Pensions. International Economic Review 44, 917-937.

Glomm, G. and B. Ravikumar, 1992. Public versus Private Investment in Human Capital: Endogenous Growth and Income Inequality. Journal of Political Economy 100, 818-834.

Goldhaber, D. and E. Anthony, 2007. Can Teacher Quality Be Effectively Assessed? National Board Certification As a Signal of Effective Teaching. Review of Economics and Statistics 89, 134-150.

Goldhaber, D. and A. Liu, 2003. Occupational Choices and the Academic Proficiency of the Teacher Workforce. In: W. Fowler (ed.), Developments in School Finance 2001-02. NCES, Washington, DC, pp. 53-75.

Hanushek, E., 1999. Some Findings from an Independent Investigation of the Tennessee STAR Experiment and from Other Investigations of Class Size Effects. Educational Evaluation and Policy Analysis, 21, 143-163.

Hanushek, E., J. Kain, D. O'Brien, and S. Rivkin., 2005. The Market for Teacher Quality. NBER Working Paper 11154.

Hanushek, E. and S. Rivkin, 1997. Understanding the Twentieth Century Growth in U.S. School Spending. Journal of Human Resources 32, 35-68.

Hanushek, E. and S. Rivkin, 2004. How to Improve the Supply of High-Quality Teachers. Brookings Papers on Education Policy, 7-44.

Hatsor, L., 2008. The Allocation of Public Education Resources. Tel Aviv University, Foerder Working Papers, 1-08.

Hoxby, C., 1996. How Teachers' Unions Affect Education Production. Quarterly Journal of Economics 111, 671-718.

Hoxby, C. and A. Leigh, 2004. Pulled Away or Pushed Out? Explaining the Decline of Teacher Aptitude in the United States. American Economic Review Papers and Proceedings 94, 236240.

Huggett, M., G. Ventura, and A. Yaron, 2006. Human Capital and Earnings Distribution Dynamics. Journal of Monetary Economics 53, 265-290.

Jepsen, C. and S. Rivkin, 2002. What is the Tradeoff Between Smaller Classes and Teacher Quality? NBER Working Paper No. W9205.

Krueger, A., 1999. Experimental Estimates of Education Production Functions. Quarterly Journal of Economics 114, 497-532.

Krueger, A. and D. Whitmore, 2001. The Effect of Attending a Small Class in the Early Grades on College-Test Taking and Middle School Test Results: Evidence from Project STAR. Economic Journal 111, 1-28.

Lakdawalla, D., 2006. The Economics of Teacher Quality. Journal of Law and Economics 49, 285-329.

LeGrand, J., 1982. The Strategy of Equality Redistribution and the Social Services. George Allen and Unwin, London. 
Leitner, J., 2000. Earnings within Education Groups and Overall Productivity Growth. Journal of Political Economy 108, 807-832.

Lucas, R., 1988. On the Mechanics of Economic Development. Journal of Monetary Economics 22, $3-42$.

Rangazas, P., 2002. The Quantity and Quality of Schooling and U.S. Labor Productivity Growth (1870-2000). Review of Economic Dynamics 5, 932-964.

Restuccia, D. and C. Urrutia, 2004. Intergenerational Persistence of Earnings: the Role of Early and College Education. American Economic Review 94, 1354-1378.

Rivkin, S., E. Hanushek, and J. Kain, 2005. Teachers, Schools and Academic Achievement. Econometrica 73, 417-458.

Rosen, S., 1976. “A Theory of Life Earnings,” Journal of Political Economy 84, S45-S67.

Stoddard, Christiana, 2003. Why Has the Number of Teachers per Student Risen While Teacher Quality Has Declined? The Role of Changes in the Labor Market for Women. Journal of Urban Economics 53, 458-481.

Su, X., 2004. The Allocation of Public Funds in a Hierarchical Educational System. Journal of Economic Dynamics and Control 28, 2485-2510.

Tamura, R., 2001. Teachers, Growth, and Convergence. Journal of Political Economy 109, 10211059. 


\section{Appendix 1}

The Basic Education Quality Optimization Problem under the Collective Bargaining Regime Thanks to Assumption 1 of the uniform distribution of innate ability on the interval $[a, A]$ and according to the basic and advanced education production functions (4) and (5) we can simplify expressions (8) and (23), respectively, as

$$
\begin{gathered}
E_{t}^{C B}=\left(z_{t}^{C B}\right)^{\gamma}\left(q_{t}^{C B}\right)^{v}=\frac{z_{t}^{\gamma}\left[\bar{h}_{t}^{2}-\underline{h}_{t}^{2}\right]^{\nu}}{\left[2(b+B) A C E_{t-1}^{C B}\right]^{v}} \\
z_{t}^{C B}=\frac{\bar{h}_{t}^{C B}-\underline{h}_{t}^{C B}}{(b+B) A C E_{t-1}^{C B}}
\end{gathered}
$$

and therefore problem (26) to maximize the quality of basic education $E_{t}$ subject to the budget constraint can be restated as

$$
\max _{z_{t}, h_{t}} \frac{z_{t}^{\gamma}\left[\bar{h}_{t}^{2}-\underline{h}_{t}^{2}\right]^{\nu}}{\left[2(b+B) A C E_{t-1}^{C B}\right]^{\nu}}
$$

subject to (A1)

$$
\begin{aligned}
& z_{t}^{C B} \theta_{t} w \bar{h}_{t}^{C B}=T_{t}^{C B} \\
& \underline{a}_{t}^{C B} \geq a_{t}^{* C B}
\end{aligned}
$$

or equivalently, according to (A1), as

$$
\begin{aligned}
\max _{z_{t}, \bar{h}_{t}} & 2^{-v}\left(\bar{h}_{t}+\underline{h}_{t}\right)^{v} z_{t}^{\gamma+v} \\
\text { subject to } & z_{t}^{C B} \theta_{t} w \bar{h}_{t}^{C B}=T_{t}^{C B} \\
& \underline{a}_{t}^{C B} \geq a_{t}^{* C B}
\end{aligned}
$$

Note that the optimal lower and upper cut-off levels of teachers' human capital $\bar{h}_{t}^{C B}, \underline{h}_{t}^{C B}$ are related through the optimal choice of their number $z_{t}^{C B}$ according to equation (A1). The optimization in problem (A2) thus expresses the trade-off between the quantity and quality of teachers to be hired. The quality of the top teacher $\bar{h}_{t}$ will not only determine his salary $I_{t}^{h}=\theta_{t} w_{t} \bar{h}_{t}$ due to his outside option as a skilled worker, but will set the identical salary for all 
other teachers according to the equal pay based collective bargaining agreement. Conversely, teacher salary $I_{t}^{h}$ set by the education agency will uniquely determine the top teacher quality $\bar{h}_{t}$. Therefore the total teachers' wage bill in the education budget constraint is given by $z_{t} \theta_{t} w_{t} \bar{h}_{t}$.

Therefore using relationships (24) to express $\bar{h}_{t}$ and $\underline{h}_{t}$ and then eliminate $\underline{a}_{t}$ according to formula (25), we obtain

$$
q_{t}^{C B}=\frac{\bar{h}_{t}^{2}-\underline{h}_{t}^{2}}{2(b+B) A C E_{t-1}^{C B}}=\left[(b+B) C E_{t-1}^{C B} \bar{a}_{t}^{C B}-B h^{*}-\frac{1}{2} z_{t}^{C B}(b+B) A C E_{t-1}^{C B}\right] z_{t}^{C B}
$$

so we can restate the education quality optimization problem (A3) as

$$
\begin{aligned}
& \max _{z_{t}, \bar{a}_{t}} E_{t}^{C B}=2^{-v}\left[2(b+B) C E_{t-1}^{C B} \bar{a}_{t}^{C B}-2 B h^{*}-z_{t}^{C B}(b+B) A C E_{t-1}^{C B}\right]^{v} z_{t}^{\gamma+v} \\
& \text { subject to } z_{t}^{C B} \theta_{t} w\left[(b+B) C E_{t-1}^{C B} \bar{a}_{t}^{C B}-B h^{*}\right]=T_{t}^{C B} \text { and } \\
& \bar{a}_{t}^{C B}-A z_{t}^{C B} \geq a_{t}^{*}
\end{aligned}
$$

\section{Assumptions of the Model}

We will now spell out specific conditions on the model's parameters behind the Assumption 2 outlined in Section 4 of the paper. We impose the following restrictions on the economy's

parameters, where $E_{-1}$ is an exogenously given per student basic education quality provided to generation $G_{0}$ individuals.

Assumption 2. The returns to the human capital of teachers are non-decreasing: $v \geq 1$. Furthermore, the following inequalities are true for $t=0,1, \ldots$ :

$$
\begin{aligned}
& \text { (i) }\left(\frac{v}{\gamma}(b+B) A C\left(1-\tau_{t}\right)\right)^{\frac{1}{2+\gamma / v}}\left(\left(\frac{\gamma}{2 v+\gamma}\right)\left(\frac{\tau_{t}}{1-\tau_{t}}\right)\right)^{\frac{1+\gamma / 2 v}{2+\gamma / v}}\left(1-\frac{B h^{*}}{(b+B) A C E_{-1}}\right)>1 \\
& \text { (ii) }\left(\frac{v\left(1-\tau_{t}\right)}{\gamma}-\frac{1}{2}\right)\left(\left(\frac{\gamma}{2 v+\gamma}\right)\left(\frac{\tau_{t}}{1-\tau_{t}}\right)\right)^{1 / 2}\left(1-\frac{B h^{*}}{(b+B) A C E_{-1}}\right)>\frac{1}{\theta_{t}(b+B)}
\end{aligned}
$$

The main thrust of the above conditions concerns the parameters which characterize educational gains. Inequality (i) is satisfied, if parameter $C$ characterizing the human capital gains in basic education according to (4) is sufficiently large. Inequality (ii) will hold if $(b+B)$, 
a productivity characteristic of the college education production function (5), is large enough.

Assumption 2 also requires that education taxes $\tau_{t}$ were not too small (the above inequalities imply a uniform lower bound for $\tau_{t}$ ) while not exceeding $1-\frac{\gamma}{2 v}$. Indeed, $\tau_{t} \leq 1-\frac{\gamma}{2 v}$ must be true in order for the term $\left(\frac{v\left(1-\tau_{t}\right)}{\gamma}-\frac{1}{2}\right)$ in the above condition (ii) to be positive. As discussed in Section 4, the inequality $\tau_{t} \leq 1-\frac{\gamma}{2 v}$ imposes a requirement that $\gamma$, the relative importance of the teacher-student ratio for schooling effectiveness, should not be substantially greater than $v$, the relative importance of the teacher quality.

We will now proceed to proving Proposition 2, the Lemmas, Corollaries, and Theorems. We will first prove Proposition 2 and Lemmas 1 and 2 under the hypothesis that Lemma 3 is correct, i.e. that the cut-off ability $a_{t}^{* C B}$ of college attendees satisfies formula (6). We will then prove that Lemma 3 is indeed correct in the recursive dynamic equilibrium, and thereby the imposition of the hypothesis does not diminish the generality of (or create circularity problems with) the argument.

\section{Proof of Proposition 2}

According to the teacher salary equation (22) and the tax revenue formula (27), the budget constraint in the education quality optimization problem can be rewritten as

$$
\left(1-\tau_{t}\right) z_{t}^{C B} \theta_{t} \bar{h}_{t}^{C B}=\tau_{t}\left(L_{t}+\theta_{t} H_{t}^{y}\right)
$$

Using the education production functions (4) and (5) and the assumption that innate ability is uniformly distributed on $[0, A]$ we can express the aggregate supply of unskilled and skilled labor, respectively, as

$$
\begin{gathered}
L_{t}=\int_{0 \leq a(\omega) \leq a_{t}^{*}} l_{t}(\omega) d \mu_{t}(\omega)=C E_{t-1}^{C B} \int_{0}^{a_{t}^{*}} \frac{a}{A} d a=\frac{\left(a_{t}^{*}\right)^{2}}{2 A} C E_{t-1}^{C B} \\
H_{t}^{y}=\int_{\bar{a}_{t}^{C B} \leq a(\omega) \leq A} h_{t}(\omega) d \mu_{t}(\omega)=\int_{a_{t}^{*}}^{A}\left[(b+B) C E_{t-1}^{C B} a-B h^{*}\right] \frac{1}{A} d a-\int_{\underline{a}_{t}^{C B}}^{\bar{a}_{t}^{C B}}\left[(b+B) C E_{t-1}^{C B} a-B h^{*}\right] \frac{1}{A} d a \\
=\frac{(b+B) C E_{t-1}^{C B}}{2 A}\left[A^{2}-\left(a_{t}^{* C B}\right)^{2}-\left(\bar{a}_{t}^{C B}\right)^{2}+\left(\underline{a}_{t}^{C B}\right)^{2}\right]-\frac{B h^{*}}{A}\left[A-a_{t}^{* C B}-\bar{a}_{t}^{C B}+\underline{a}_{t}^{C B}\right]
\end{gathered}
$$


Therefore expressing $\bar{h}_{t}$ through $\bar{a}_{t}$ according to the relationship in (24) we can rewrite the budget constraint (A5) as

$$
\begin{aligned}
& \left(1-\tau_{t}\right) \theta_{t} z_{t}^{C B}\left((b+B) C E_{t-1}^{C B} \bar{a}_{t}^{C B}-B h^{*}\right)= \\
& \quad \frac{\tau_{t} C E_{t-1}^{C B}}{2 A}\left[\left(a_{t}^{* C B}\right)^{2}+\theta_{t}(b+B)\left(A^{2}-\left(a_{t}^{*} C B\right)^{2}-\left(\bar{a}_{t}^{C B}\right)^{2}+\left(\underline{a}_{t}^{C B}\right)^{2}\right)\right]-\frac{\tau_{t} \theta_{t} B h^{*}}{A}\left[A-a_{t}^{* C B}-\bar{a}_{t}^{C B}+\underline{a}_{t}^{C B}\right]
\end{aligned}
$$

We now eliminate variables $a_{t}^{*}$ and $\underline{a}_{t}$ from (A8) by substituting the value of $a_{t}^{*}$ given by (6) according to Lemma 3, and using the expression (25). This immediately turns expression (A8) into a linear equation in terms of variable $\bar{a}_{t}$ which yields

$$
\bar{a}_{t}^{C B}=\frac{z_{t}^{C B} \tau_{t} A}{2}+\frac{B h^{*}}{(b+B) C E_{t-1}^{C B}}+\frac{\tau_{t} A}{2 z_{t}^{C B}} J_{t}^{C B}
$$

where $J_{t}^{C B}$ is as defined by formula (29). Expression (A9) incorporates the education budget constraint of the optimization problem (A4). That problem's objective function, upon substituting the expression (A5) for $\bar{a}_{t}$, becomes a function of a single variable $z_{t}$. We will first solve for its unconstrained maximization and then discuss the verification that its solution satisfies the only remaining constraint $\bar{a}_{t}^{C B}-A z_{t}^{C B} \geq a_{t}^{* C B}$ in the optimization problem (A4).

Thus we are looking at the unconstrained maximization of the following function:

$$
F\left(z_{t}^{C B}\right)=q_{t}^{v} z_{t}^{\gamma}=\left(\frac{\tau_{t}(b+B) A C E_{t-1}^{C B}}{2}-\tau_{t} B h^{*}+\frac{\tau_{t} \theta_{t} B^{2} h^{* 2}}{2\left(\theta_{t}(b+B)-1\right) A C E_{t-1}^{C B}}-\frac{\left(1-\tau_{t}\right)(b+B) A C E_{t-1}^{C B} z_{t}^{2}}{2}\right)^{v} z_{t}^{\gamma}
$$

Its first order necessary condition is given by the equation

$$
\gamma z_{t}^{\gamma-1} q_{t}^{v}-v\left(1-\tau_{t}\right)(b+B) A C E_{t-1} z_{t}^{\gamma+1} q_{t}^{v-1}=0
$$

yielding unique non-negative solution:

$$
z_{t}^{C B}=\left(\left(\frac{\gamma}{2 v+\gamma}\right)\left(\frac{\tau_{t}}{1-\tau_{t}}\right)\right)^{1 / 2}\left(J_{t}^{C B}\right)^{1 / 2}
$$

It is straightforward to verify that this solution also satisfies the second order sufficient condition of the maximization problem.

Substituting (A11) in (A10) we obtain the expression for the aggregate teacher quality:

$$
q_{t}^{C B}=\frac{v \tau_{t}(b+B) A C E_{t-1}^{C B}}{2 v+\gamma} J_{t}^{C B}
$$


Substituting expression (A11) back into formula (A9) we obtain

$$
\bar{a}_{t}^{C B}=\frac{\tau_{t} A z_{t}^{C B}}{2}+\frac{B h^{*}}{(b+B) C E_{t-1}^{C B}}+\frac{\tau_{t} A}{2 z_{t}^{C B}} J_{t}^{C B}
$$

which simplifies, by using equation (A11) again, into

$$
\bar{a}_{t}^{C B}=\frac{B h^{*}}{(b+B) C E_{t-1}^{C B}}+A z_{t}^{C B}\left(\frac{v\left(1-\tau_{t}\right)}{\gamma}+\frac{1}{2}\right)
$$

Combining this with (25) we obtain

$$
\underline{a}_{t}^{C B}=\frac{B h^{*}}{(b+B) C E_{t-1}^{C B}}+A z_{t}^{C B}\left(\frac{v\left(1-\tau_{t}\right)}{\gamma}-\frac{1}{2}\right)
$$

As discussed earlier, in order to ascertain that the expressions (A11), (A13), (A14) represent the solution of the constrained optimization problem (A4), it remains to verify that the constraint $\underline{a}_{t}>a_{t}^{*}$ does hold for $\underline{a}_{t}$ given by (A14). This will be indeed demonstrated in the proof of Lemma 2 below.

Observe that the education policy optimization as well as the individuals' and the production sector's general equilibrium reactions are determined recursively. Indeed, according to expressions (A11), (A13), and (A14), education quality $E_{t-1}^{C B}$ uniquely determines optimal education policy in period $t$, i.e. the number of teachers, as well as the range of their innate abilities and thereby, due to (24), the range of their human capital attainment. This in turn will uniquely determine college attendance and employment decisions by generation $t$ individuals, hence their incomes and their allocations. The education agency's policy will also determine the current period's basic education quality $E_{t}$, so the recursion continues.

\section{$\underline{\text { Proof of Lemma } 1}$}

According to (A4), $E_{t}^{C B}=\left(z_{t}^{C B}(b+B) C E_{t-1}^{C B} \bar{a}_{t}^{C B}-z_{t}^{C B} B h^{*}-\frac{1}{2}(b+B) A C E_{t-1}^{C B}\left(z_{t}^{C B}\right)^{2}\right)^{v}\left(z_{t}^{C B}\right)^{\gamma}$.

Substituting the expression for $\bar{a}_{t}$ in (A13), we obtain

$$
\begin{gathered}
E_{t}^{C B}=\left(A(b+B) C E_{t-1}^{C B}\left(\frac{v\left(1-\tau_{t}\right)}{\gamma}\right)\right)^{v}\left(z_{t}^{C B}\right)^{2 v+\gamma}, \text { or according to (A11) } \\
E_{t}^{C B}=\left(\frac{A(b+B) C E_{t-1}^{C B} \nu\left(1-\tau_{t}\right)}{\gamma}\right)^{v}\left(\frac{\gamma}{2 v+\gamma} \frac{\tau_{t}}{1-\tau_{t}} J_{t}^{C B}\right)^{v+\gamma / 2}
\end{gathered}
$$


Note that since $\frac{\theta_{t}(b+B)}{\theta_{t}(b+B)-1}>1$, the following inequality is true

$$
J_{t}^{C B}>\left[1-\frac{B h^{*}}{(b+B) A C E_{t-1}^{C B}}\right]^{2}
$$

Therefore we can write

$$
E_{t}^{C B}>\left(\frac{v}{\gamma}(b+B) A C E_{t-1}^{C B}\left(1-\tau_{t}\right)\right)^{v}\left(\left(\frac{\gamma}{2 v+\gamma}\right)\left(\frac{\tau_{t}}{1-\tau_{t}}\right)\right)^{v+\gamma / 2}\left(1-\frac{B h^{*}}{(b+B) A C E_{t-1}^{C B}}\right)^{2 v+\gamma}
$$

Thus, in order to prove the Lemma it is sufficient to show that for all $t=0,1, \ldots$

$$
\left(\frac{v}{\gamma}(b+B) A C\left(1-\tau_{t}\right)\right)^{\frac{1}{2+\gamma / v}}\left(\left(\frac{\gamma}{2 v+\gamma}\right)\left(\frac{\tau_{t}}{1-\tau_{t}}\right)\right)^{\frac{1+\gamma / 2 v}{2+\gamma / v}}\left(1-\frac{B h^{*}}{(b+B) A C E_{t-1}^{C B}}\right)>1
$$

which is indeed true according to Assumption 2(i) and by the induction argument.

\section{Proof of Lemma 2}

Based on Lemma 3 we use expression (6) for $a_{t}^{* C B}$. Then according to (A14) our task of proving the inequality $\underline{a}_{t}^{C B}>a_{t}^{* C B}$ is equivalent to verifying the inequality

$$
\begin{aligned}
& \frac{B h^{*}}{(b+B) C E_{t-1}^{C B}}+A z_{t}^{C B}\left(\frac{v\left(1-\tau_{t}\right)}{\gamma}-\frac{1}{2}\right)>\frac{1}{C E_{t-1}^{C B}} \frac{\theta_{t} B h^{*}}{\theta_{t}(b+B)-1} \\
& \text { or } A z_{t}^{C B}\left(\frac{v\left(1-\tau_{t}\right)}{\gamma}-\frac{1}{2}\right)>\frac{1}{(b+B) C E_{t-1}^{C B}} \frac{B h^{*}}{\theta_{t}(b+B)-1}
\end{aligned}
$$

Upon substituting the expression (A11) for $z_{t}$, the last inequality becomes

$$
A\left(\frac{v\left(1-\tau_{t}\right)}{\gamma}-\frac{1}{2}\right)\left(\left(\frac{\gamma}{2 v+\gamma}\right)\left(\frac{\tau_{t}}{1-\tau_{t}}\right)\right)^{1 / 2}\left(J_{t}^{C B}\right)^{1 / 2}>\frac{1}{(b+B) C E_{t-1}^{C B}} \frac{B h^{*}}{\theta_{t}(b+B)-1}
$$

Under Lemma 3 the right hand side in (A16) is smaller than $\frac{A}{\theta_{t}(b+B)}$ since $a_{t}^{*}<A$. Therefore according to (A15) in order to prove the inequality (A16) it is by far sufficient to establish

$$
\left(\frac{v\left(1-\tau_{t}\right)}{\gamma}-\frac{1}{2}\right)\left(\frac{\gamma}{2 v+\gamma} \frac{\tau_{t}}{1-\tau_{t}}\right)^{1 / 2}\left(1-\frac{B h^{*}}{(b+B) A C E_{t-1}^{C B}}\right)>\frac{1}{\theta_{t}(b+B)}
$$

which is indeed true for all $t=0,1, \ldots$ according to Assumption 2(ii) combined with Lemma 1. 


\section{Proof of Lemma 3}

The above proofs were based on the hypothesis that Lemma 3 is correct, i.e., that the ability cutoff for college attendance $a_{t}^{*}$ satisfies equality (6). Thus we have proved that if the college attendance cut-off ability is $a_{t}^{* C B}=\frac{1}{C E_{t-1}^{C B}} \frac{\theta_{t} B h^{*}}{\theta_{t}(b+B)-1}$ then the optimal education policy requires that all teachers' ability strictly exceed this threshold. This in turn means that the marginal college graduate will be employed in the production sector. As we explained after stating the equality (6), if an individual with ability below $a_{t}^{*}$ attended college, his skilled human capital adjusted for the net productivity augmentation $\theta_{t}$ would be inferior to his unskilled human capital derived from the first stage of education, therefore a job in production sector's skilled labor force would not compel such individual to attend college. Thus the only way the violation of Lemma 3 could occur is if such individual had an opportunity to be hired as a teacher. Compare, however, the optimization problem (26) where $a_{t}^{* C B}<\frac{1}{C E_{t-1}^{C B}} \frac{\theta_{t} B h^{*}}{\theta_{t}(b+B)-1}$ to the one with $a_{t}^{*}=\frac{1}{C E_{t-1}^{C B}} \frac{\theta_{t} B h^{*}}{\theta_{t}(b+B)-1}$. One can easily see that the only difference would be lower tax revenue $T_{t}^{C B}$ in the former case. Therefore such education policy would be inferior to the one where $a_{t}^{* C B}=\frac{1}{C E_{t-1}^{C B}} \frac{\theta_{t} B h^{*}}{\theta_{t}(b+B)-1}$. Thus the latter indeed characterizes the recursive dynamic equilibrium optimum, i.e., Lemma 3 is correct.

\section{Proof of Proposition 3}

Based on the income formulas (2)-(3), the human capital accumulation formulas (4)-(5) and using the uniform distribution of abilities as well as the formula (9) for the threshold ability between the groups, we can obtain the mean income of unskilled individuals:

$$
\bar{I}_{t}^{u}=\frac{I_{t}^{u}\left(a_{t}^{*}\right)}{2}=\frac{w \theta_{t} B h^{*}}{2\left(\theta_{t}(b+B)-1\right)}=\frac{w C E_{t-1}^{C B} a_{t}^{*}}{2}
$$

and the mean income of the skilled (ignoring the distortion due to collective bargaining in the education sector): 


$$
\bar{I}_{t}^{s}=\frac{I_{t}^{s}\left(a_{t}^{*}\right)+I_{t}^{s}(A)}{2}=\frac{w \theta_{t}}{2}\left(\frac{(b+B) \theta_{t} B h^{*}}{\left(\theta_{t}(b+B)-1\right)}+A(b+B) C E_{t-1}^{C B}-2 B h^{*}\right)
$$

Thus the inequality between the groups can be characterized by

$$
\sigma_{t}^{s / u}=\frac{\bar{I}_{t}^{s}}{\bar{I}_{t}^{u}}=\frac{A(b+B) C E_{t-1}^{C B}\left(\theta_{t}(b+B)-1\right)}{B h^{*}}+\left(2-\theta_{t}(b+B)\right)
$$

This expression obviously increases in basic education quality, which according to Lemma 1 rises over time.

The inequality within the skilled group (ignoring the aforementioned distortion) is characterized by

$$
\sigma_{t}^{s}=\frac{I_{t}^{s}(A)}{I_{t}^{s}\left(a_{t}^{*}\right)}=\frac{(b+B) A C E_{t-1}^{C B}-B h^{*}}{(b+B) a_{t}^{*} C E_{t-1}^{C B}-B h^{*}}=\left(\theta_{t}(b+B)-1\right) \frac{(b+B) A C E_{t-1}^{C B}-B h^{*}}{B h^{*}}
$$

Using formula (6) we can rewrite this as

$$
\sigma_{t}^{s}=\frac{\theta_{t}(b+B)}{a_{t}^{*}}\left(A-\frac{B h^{*}}{C E_{t-1}}\right)
$$

which too grows with the rise of basic education quality.

\section{Proof of Lemma 4}

By differentiating expressions (6) and (A11) we immediately obtain:

$$
\begin{gathered}
\frac{\partial a_{t}^{* C B}}{\partial E_{t-1}^{C B}}=\frac{-\theta_{t} B h^{*}}{\left(\theta_{t}(b+B)-1\right) C\left(E_{t-1}^{C B}\right)^{2}}<0 \\
\frac{\partial z_{t}^{C B}}{\partial E_{t-1}^{C B}}=\frac{1}{z_{t}^{C B}}\left(\frac{\gamma}{2 v+\gamma}\right)\left(\frac{\tau_{t}}{1-\tau_{t}}\right) \frac{B h^{*}}{(b+B) A C\left(E_{t-1}^{C B}\right)^{2}}\left(1-\frac{a_{t}^{*}}{A}\right)>0
\end{gathered}
$$

According to (A13) and (A14), respectively, we can write

$$
\begin{aligned}
\frac{\partial \bar{a}_{t}^{C B}}{\partial E_{t-1}^{C B}} & =-\frac{B h^{*}}{(b+B) C\left(E_{t-1}^{C B}\right)^{2}}+\frac{A}{z_{t}^{C B}}\left(\frac{2 v\left(1-\tau_{t}\right)+\gamma}{2 \gamma}\right)\left(\frac{\gamma}{2 v+\gamma}\right)\left(\frac{\tau_{t}}{1-\tau_{t}}\right) \frac{B h^{*}}{(b+B) A C\left(E_{t-1}^{C B}\right)^{2}}\left(1-\frac{a_{t}^{*}}{A}\right) \\
& =\frac{B h^{*}}{(b+B) C\left(E_{t-1}^{C B}\right)^{2}}\left(-1+z_{t}^{-1}\left(\frac{2 v\left(1-\tau_{t}\right)+\gamma}{2 \gamma}\right)\left(\frac{\gamma}{2 v+\gamma}\right)\left(\frac{\tau_{t}}{1-\tau_{t}}\right)\left(1-\frac{a_{t}^{*}}{A}\right)\right)
\end{aligned}
$$




$$
\begin{aligned}
\frac{\partial \underline{a}_{t}^{C B}}{\partial E_{t-1}^{C B}} & =-\frac{B h^{*}}{(b+B) C\left(E_{t-1}^{C B}\right)^{2}}+A z_{t}^{-1}\left(\frac{2 v\left(1-\tau_{t}\right)-\gamma}{2 \gamma}\right)\left(\frac{\gamma}{2 v+\gamma}\right)\left(\frac{\tau_{t}}{1-\tau_{t}}\right) \frac{B h^{*}}{(b+B) A C\left(E_{t-1}^{C B}\right)^{2}}\left(1-\frac{a_{t}^{*}}{A}\right) \\
& =\frac{B h^{*}}{(b+B) C\left(E_{t-1}^{C B}\right)^{2}}\left(-1+z_{t}^{-1}\left(\frac{2 v\left(1-\tau_{t}\right)-\gamma}{2 \gamma}\right)\left(\frac{\gamma}{2 v+\gamma}\right)\left(\frac{\tau_{t}}{1-\tau_{t}}\right)\left(1-\frac{a_{t}^{*}}{A}\right)\right)
\end{aligned}
$$

According to (A11) and (A15) we can write

$$
\begin{aligned}
z_{t}^{C B} & >\left(\left(\frac{\gamma}{2 v+\gamma}\right)\left(\frac{\tau_{t}}{1-\tau_{t}}\right)\right)^{1 / 2}\left(1-\frac{B h^{*}}{(b+B) A C E_{t-1}}\right)>\left(\left(\frac{\gamma}{2 v+\gamma}\right)\left(\frac{\tau_{t}}{1-\tau_{t}}\right)\right)^{1 / 2}\left(1-\frac{\theta_{t} B h^{*}}{\left(\theta_{t}(b+B)-1\right)\left(A C E_{t-1}^{C B}\right)}\right) \\
& =\left(\left(\frac{\gamma}{2 v+\gamma}\right)\left(\frac{\tau_{t}}{1-\tau_{t}}\right)\right)^{1 / 2}\left(1-\frac{a_{t}^{*}}{A}\right)
\end{aligned}
$$

Thus the expression (A20) will be negative as long as the inequality

$$
\left(\left(\frac{\gamma}{2 v+\gamma}\right)\left(\frac{\tau_{t}}{1-\tau_{t}}\right)\right)^{1 / 2}>\left(\frac{\gamma}{2 \nu+\gamma}\right)\left(\frac{\tau_{t}}{1-\tau_{t}}\right)\left(\frac{2 v\left(1-\tau_{t}\right)+\gamma}{2 \gamma}\right)
$$

is true, or equivalently $\frac{\gamma}{2 v+\gamma} \frac{\tau_{t}}{1-\tau_{t}}>\left(\frac{\gamma}{2 v+\gamma}\right)^{2}\left(\frac{\tau_{t}}{1-\tau_{t}}\right)^{2}\left(\frac{2 v\left(1-\tau_{t}\right)+\gamma}{2 \gamma}\right)^{2}$ which can be simplified as: $\left(1-\tau_{t}\right)\left(2 \frac{v}{\gamma}+1\right)>\tau_{t}\left(\frac{v}{\gamma}\left(1-\tau_{t}\right)+\frac{1}{2}\right)^{2}$. This last inequality is certainly true if $\left(1-\tau_{t}\right)\left(2 \frac{v}{\gamma}+1\right)>\tau_{t}\left(\frac{v}{\gamma}\left(1-\tau_{t}\right)+\frac{1}{2}\right)^{2}$ which reduces to $\tau_{t}<\frac{4}{5+2 v / \gamma}$. The latter is guaranteed by the condition $\tau_{t}<1-\frac{\gamma}{2 v}$, which is imposed by Assumption 2 (ii). Thus we have proven the negativity of the expression (A20).

Comparing (A20) and (A21) one can see that negativity of (A20) implies the same for (A21). Therefore we can conclude that $\frac{\partial \bar{a}_{t}^{C B}}{\partial E_{t-1}^{C B}}<0, \frac{\partial \underline{a}_{t}^{C B}}{\partial E_{t-1}^{C B}}<0$, completing the Lemma's proof.

\section{Proof of Corollary to Theorem 1}

Recall that according to relationships (24)

$$
\underline{h}_{t}^{C B}=\underline{a}_{t}^{C B}(b+B) C E_{t-1}^{C B}-B h^{*} \quad \text { and } \quad \bar{h}_{t}^{C B}=\bar{a}_{t}^{C B}(b+B) C E_{t-1}^{C B}-B h^{*}
$$

Therefore due to (A13) and (A14), respectively, as well as to (A11) we can write 


$$
\begin{aligned}
\bar{h}_{t}^{C B} & =(b+B) A C E_{t-1}^{C B}\left(\frac{v\left(1-\tau_{t}\right)}{\gamma}-\frac{1}{2}\right) z_{t}^{C B} \\
& =(b+B) C A\left(\frac{\nu\left(1-\tau_{t}\right)}{\gamma}-\frac{1}{2}\right)\left(\left(\frac{\gamma}{2 v+\gamma}\right)\left(\frac{\tau_{t}}{1-\tau_{t}}\right)\right)^{1 / 2}\left(E_{t-1}^{2}-\frac{2 B h^{*} E_{t-1}}{(b+B) A C}+\frac{\theta_{t}\left(B h^{*}\right)^{2}}{\left(\theta_{t}(b+B)-1\right)(b+B)(A C)^{2}}\right)^{1 / 2} \\
\underline{h}_{t}^{C B} & =(b+B) A C E_{t-1}^{C B}\left(\frac{v\left(1-\tau_{t}\right)}{\gamma}+\frac{1}{2}\right) z_{t} \\
& =(b+B) A C\left(\frac{v\left(1-\tau_{t}\right)}{\gamma}+\frac{1}{2}\right)\left(\left(\frac{\gamma}{2 v+\gamma}\right)\left(\frac{\tau_{t}}{1-\tau_{t}}\right)\right)^{1 / 2}\left(E_{t-1}^{2}-\frac{2 B h^{*} E_{t-1}}{(b+B) A C}+\frac{\theta_{t}\left(B h^{*}\right)^{2}}{\left(\theta_{t}(b+B)-1\right)(b+B)(A C)^{2}}\right)^{1 / 2}
\end{aligned}
$$

both increasing functions of $E_{t-1}^{C B}$. Indeed, the derivative of each is proportionate to the expression $1-\frac{B h^{*}}{(b+B) A C E_{t-1}^{C B}}$, which is positive as shown by (A17).

\section{Proof of Theorem 2}

The proof will proceed by the induction argument.

Consider first the effect of a positive shock to coefficient $\theta_{t}$ in period $t=t_{0}$ on education policy variables in this same period. According to (A11) direct derivative $\frac{\partial z_{t}^{C B}}{\partial \theta_{t}}$ has the same sign as $\frac{\partial}{\partial \theta_{t}}\left[\frac{\theta_{t}}{\theta_{t}(b+B)-1}\right]$, i.e. negative, so we can write

$$
\frac{\partial z_{t}^{C B}}{\partial \theta_{t}}<0
$$

Therefore, according to (A13) and (A14), respectively, we can write

$$
\begin{gathered}
\frac{\partial \bar{a}_{t}^{C B}}{\partial \theta_{t}}=\frac{\partial \bar{a}_{t}^{C B}}{\partial z_{t}^{C B}} \frac{\partial z_{t}^{C B}}{\partial \theta_{t}}=A\left(\frac{3}{2}-\tau_{t}\right) \frac{\partial z_{t}^{C B}}{\partial \theta_{t}}<0 \\
\frac{\partial \underline{a}_{t}^{C B}}{\partial \theta_{t}}=\frac{\partial a_{t}^{C B}}{\partial z_{t}^{C B}} \frac{\partial z_{t}^{C B}}{\partial \theta_{t}}=A\left(\frac{1}{2}-\tau_{t}\right) \frac{\partial z_{t}^{C B}}{\partial \theta_{t}}<0
\end{gathered}
$$

Recall that according to the derivation of (A4)

$$
q_{t}^{C B}=\left[(b+B) C E_{t-1}^{C B} \bar{a}_{t}^{C B}-B h^{*}-\frac{1}{2} z_{t}^{C B} A(b+B) C E_{t-1}^{C B}\right] z_{t}^{C B}
$$


Using formula (A13) we can rewrite the above as

$$
q_{t}^{C B}=\frac{v\left(1-\tau_{t}\right)}{\gamma}(b+B) A C E_{t-1}^{C B}\left(z_{t}^{C B}\right)^{2}
$$

which implies, according to (A23), that

$$
\frac{\partial q_{t}^{C B}}{\partial \theta_{t}}<0
$$

for $t=t_{0}$. Combining (A23) with (A26) and referring to (8) we can conclude that for $t=t_{0}$

$$
\frac{\partial E_{t}^{C B}}{\partial \theta_{t}}<0
$$

We can now proceed to the next step of the induction and evaluate the effect born by the education policy variables in period $t=t_{0}+1$, keeping in mind two sources of this effect: the direct effect of higher value of $\theta_{t_{0}+1}$ and the indirect one caused by lower education quality in the previous period $E_{t_{0}}$ as established in (A28). The results in (A23), (A27) and (A28) show that the direct effects on the variables $z_{t+1}, q_{t+1}, E_{t+1}$ in any period $t+1$ of a contemporaneous rise in $\theta_{t+1}$ are negative. For the purposes of completing the induction argument it will therefore be sufficient to prove that a decline in $E_{t}$ will have a negative effect on $z_{t+1}, q_{t+1}, E_{t+1}$, in other words that the derivatives of these variables with respect to $E_{t}$ are all positive.

According to (A11) the derivative $\frac{\partial\left(z_{t+1}^{2}\right)}{\partial E_{t}}$ has the same sign as the expression $1-\frac{\theta_{t+1} B h^{*}}{\left(\theta_{t+1}(b+B)-1\right) A C E_{t-1}}$ which according to Lemma 3 is equal to $1-A^{-1} a_{t}^{*}$ and therefore is positive. Thus we can conclude that

$$
\frac{\partial z_{t+1}^{C B}}{\partial E_{t}^{C B}}>0
$$

Rewriting expression (A6) for period $t+1: \quad q_{t+1}^{C B}=A(b+B) C E_{t}^{C B} \frac{v\left(1-\tau_{t+1}\right)}{\gamma}\left(z_{t+1}^{C B}\right)^{2}$, we note that a rise in $E_{t}^{C B}$ affects $q_{t+1}^{C B}$ directly (obviously positively) as well as indirectly through $z_{t+1}^{C B}$, also positively according to (A29). We can therefore conclude that $\frac{\partial q_{t+1}^{C B}}{\partial E_{t}^{C B}}>0$. This 
combined with (A29) implies due to (8) that $\frac{\partial E_{t+1}^{C B}}{\partial E_{t}^{C B}}>0$. Thus according to the above discussion the Theorem's proof is complete.

\section{Proof of Theorem 3}

The proof will proceed by induction.

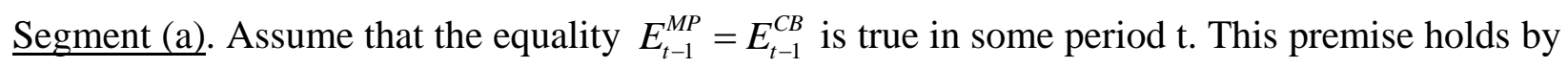
definition for $\mathrm{t}=0$, which serves as the base for our induction argument.

Based on this premise, the comparison of equations (18) and (A12) immediately yields the inequality $q_{t}^{M P}>q_{t}^{C B}$. We will now use this inequality and the induction premise $E_{t-1}^{M P}=E_{t-1}^{C B}$ to prove that $z_{t}^{M P}>z_{t}^{C B}$. Assume the contrary: $z_{t}^{M P} \leq z_{t}^{C B}$. Combining this with the above fact $q_{t}^{M P}>q_{t}^{C B}$ and using relationships (20) and (A26) we obtain the following chain of relationships:

$$
\begin{aligned}
& 2 q_{t}^{C B}<2 q_{t}^{M P}=\left(z_{t}^{M P}\right)^{2}(b+B) A C E_{t-1}^{M P}+z_{t}^{M P} \frac{2 B h^{*}}{\theta_{t}(b+B)-1} \leq \\
& \leq\left(z_{t}^{C B}\right)^{2}(b+B) A C E_{t-1}^{C B}+z_{t}^{C B} \frac{2 B h^{*}}{\theta_{t}(b+B)-1}=\frac{\gamma}{v\left(1-\tau_{t}\right)} q_{t}^{C B}+z_{t}^{C B} \frac{2 B h^{*}}{\theta_{t}(b+B)-1}
\end{aligned}
$$

or $\left(1-\frac{\gamma}{2 v\left(1-\tau_{t}\right)}\right) q_{t}^{C B}<z_{t}^{C B} \frac{B h^{*}}{\theta_{t}(b+B)-1}$. Now using the expressions (A11) and (A12) we rewrite this inequality as $\left(1-\frac{\gamma}{2 v\left(1-\tau_{t}\right)}\right) \frac{v \tau_{t}(b+B) A C E_{t-1}^{C B}}{2 v+\gamma} J_{t}^{C B}<\left(\left(\frac{\gamma}{2 \nu+\gamma}\right)\left(\frac{\tau_{t}}{1-\tau_{t}}\right)\right)^{1 / 2} \frac{\left(J_{t}^{C B}\right)^{1 / 2} B h^{*}}{\theta_{t}(b+B)-1}$ or equivalently, $\left(\frac{v\left(1-\tau_{t}\right)}{\gamma}-\frac{1}{2}\right)\left(\frac{\tau_{t}}{1-\tau_{t}}\right)^{1 / 2}\left(\frac{\gamma}{2 v+\gamma}\right)^{1 / 2}\left(J_{t}^{C B}\right)^{1 / 2}<\frac{B h^{*}}{\left(\theta_{t}(b+B)-1\right)(b+B) A C E_{t-1}^{C B}}$, the opposite of the inequality established in (A16). The obtained contradiction thus proves that $z_{t}^{M P}>z_{t}^{C B}$, provided the same prior period's education quality $E_{t-1}$. Combined with the earlier established $q_{t}^{M P}>q_{t}^{C B}$ this implies, according to (8) that, under the same premise, $E_{t}^{M P}=E_{t}^{C B}$.

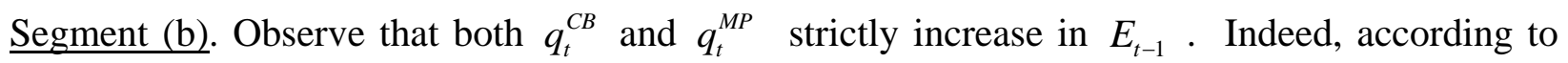
expressions (18) and (A12), derivatives of both variables have the sign of the expression 


$$
1-\frac{\theta_{t}\left(B h^{*}\right)^{2}}{\left(\theta_{t}(b+B)-1\right)(b+B)\left(A C E_{t-1}\right)^{2}}=1-\frac{a_{t}^{*}}{A} \frac{B h^{*}}{(b+B) A C E_{t-1}}
$$

which is positive because $a_{t}^{*}<A$ by definition while $\frac{B h^{*}}{(b+B) A C E_{t-1}^{C B}}<1$ according to Assumption 2 and Lemma 1. Note that inequality $\frac{B h^{*}}{(b+B) A C E_{t-1}^{M P}}<1$ is likewise true under the premise $E_{t-1}^{M P}=E_{t-1}^{C B}$, and would by far remain valid if $E_{t-1}^{M P} \geq E_{t-1}^{C B}$ was true. Thus $\frac{\partial q_{t}^{C B}}{\partial E_{t-1}^{C B}}>0, \frac{\partial q_{t}^{M P}}{\partial E_{t-1}^{M P}}>0$.

Recall that $\frac{\partial z_{t}^{C B}}{\partial E_{t-1}^{C B}}>0$ according to (A19). In order to prove that $\frac{\partial z_{t}^{M P}}{\partial E_{t-1}^{M P}}>0$ is also true, we rewrite equation (21) as $\tau_{t} J_{t}^{M P}=\left(z_{t}^{M P}\right)^{2}+z_{t}^{M P} \frac{2 B h^{*}}{\left(\theta_{t}(b+B)-1\right)(b+B) A C E_{t-1}^{M P}}$. The left-hand side of this equation increases in $E_{t-1}^{M P}$ : indeed, $\frac{\partial J_{t}^{M P}}{\partial E_{t-1}^{M P}}$ has the sign of the expression $1-\frac{\theta B h^{*}}{\left(\theta_{t}(b+B)-1\right) A C E_{t-1}^{M P}}=1-\frac{a_{t}^{* M P}}{A}$. Then by differentiating the right-hand side of the equation with respect to $E_{t-1}^{M P}$ one can easily see that $\frac{\partial z_{t}^{M P}}{\partial E_{t-1}^{M P}}>0$ must be true.

The established positive effect of $E_{t-1}^{M P}$ on $q_{t}^{M P}$ and $z_{t}^{M P}$ implies that the proofs in Segment (a) of the facts $q_{t}^{M P}>q_{t}^{C B}, \quad z_{t}^{M P}>z_{t}^{C B}$, and thereby, according to (8), of the fact $E_{t}^{M P}>E_{t}^{C B}$ remain valid if the original premise $E_{t-1}^{M P}=E_{t-1}^{C B}$ is replaced with $E_{t-1}^{M P} \geq E_{t-1}^{C B}$. This allows us to proceed with the induction argument, which consecutively establishes the inequalities $q_{t}^{M P}>q_{t}^{C B}, z_{t}^{M P}>z_{t}^{C B}, E_{t}^{M P}>E_{t}^{C B}$ for $\mathrm{t}=0,1, \ldots$, as required. This completes the proof of parts (i) and (ii) of the Theorem.

To prove part (iii), we rewrite the claimed inequality $\bar{a}_{t}^{M P}>\bar{a}_{t}^{C B}$, using the relationships (15), (6) and (A13), as

$$
z_{t}^{M P}+\frac{\theta_{t} B h^{*}}{\left(\theta_{t}(b+B)-1\right) A C E_{t-1}^{M P}}>\frac{B h^{*}}{(b+B) A C E_{t-1}^{C B}}+z_{t}^{C B}\left(\frac{v\left(1-\tau_{t}\right)}{\gamma}+\frac{1}{2}\right)
$$


and will use the line of proof similar to that used in Segment (a) in the proof above. Namely, we will initially proceed from the premise, later to be revised, that $E_{t-1}^{M P}=E_{t-1}^{C B}$. Then the above inequality can be rewritten as $z_{t}^{M P}+\frac{B h^{*}}{\left(\theta_{t}(b+B)-1\right) A C E_{t-1}^{M P}}>z_{t}^{C B}\left(\frac{v\left(1-\tau_{t}\right)}{\gamma}+\frac{1}{2}\right)$. By squaring both sides of this inequality, we obtain the following equivalent to the claimed inequality:

$$
\left(z_{t}^{M P}\right)^{2}+z_{t}^{M P} \frac{2 B h^{*}}{(b+B) A C E_{t-1}^{M P}\left(\theta_{t}(b+B)-1\right)}+\frac{\left(B h^{*}\right)^{2}}{\left(\theta_{t}(b+B)-1\right)^{2}(b+B)^{2}\left(A C E_{t-1}^{M P}\right)^{2}}>\left(z_{t}^{C B}\right)^{2}\left(\frac{v\left(1-\tau_{t}\right)}{\gamma}+\frac{1}{2}\right)^{2}
$$

which we can rewrite, according to (21), (A26), and (A12), as

$$
\tau_{t} J_{t}^{M P}+\frac{\left(B h^{*}\right)^{2}}{\left(\theta_{t}(b+B)-1\right)^{2}(b+B)^{2}\left(A C E_{t-1}^{M P}\right)^{2}}>\left(\frac{v\left(1-\tau_{t}\right)}{\gamma}+\frac{1}{2}\right)^{2} \frac{\tau_{t}}{1-\tau_{t}} \frac{\gamma}{2 v+\gamma} J_{t}^{C B}
$$

Thus we have shown that in order to prove the original claim $\bar{a}_{t}^{M P}>\bar{a}_{t}^{C B}$ it will suffice to establish the following fact $J_{t}^{M P} \geq\left(\frac{v\left(1-\tau_{t}\right)}{\gamma}+\frac{1}{2}\right)^{2} \frac{1}{1-\tau_{t}} \frac{\gamma}{2 v+\gamma} J_{t}^{C B}$. According to the initial premise of $E_{t-1}^{M P}=E_{t-1}^{C B}$ and the expression (19) we also have $J_{t}^{M P}=J_{t}^{C B}$, so we just need to ascertain that $1 \geq\left(\frac{v\left(1-\tau_{t}\right)}{\gamma}+\frac{1}{2}\right)^{2} \frac{1}{1-\tau_{t}} \frac{\gamma}{2 v+\gamma}$ holds. It is straightforward to show that this is the case iff the parametric condition $\frac{\gamma}{2 v} \geq \frac{\left(1-\tau_{t}\right)}{1+2 \sqrt{1-\tau_{t}}}$ stated in the Theorem holds.

Thus we have established the inequality $\bar{a}_{t}^{M P}>\bar{a}_{t}^{C B}$ based on the premise that $E_{t-1}^{M P}=E_{t-1}^{C B}$. It now remains to recall the fact, stated in Lemma 4, that $\bar{a}_{t}^{C B}$ decreases in $E_{t-1}^{C B}$, which implies that the fact $\bar{a}_{t}^{M P}>\bar{a}_{t}^{C B}$ will remain true if the premise $E_{t-1}^{M P}=E_{t-1}^{C B}$ is replaced with $E_{t-1}^{M P} \geq E_{t-1}^{C B}$, the factually correct one as established in part (i) of this Theorem. The proof is thus complete.

\section{Proof of Theorem 4}

Recall the facts $\frac{\partial q_{t}^{M P}}{\partial E_{t-1}^{M P}}>0$ and $\frac{\partial z_{t}^{M P}}{\partial E_{t-1}^{M P}}>0$ established in the proof of Theorem 5 for $\mathrm{t}=0,1, \ldots$ They imply, according to (8), that $\frac{\partial E_{t}^{M P}}{\partial E_{t-1}^{M P}}>0$ is also true at all times. According to Lemma 1, 
$E_{0}^{C B}>E_{-1}^{C B}$, while by assumption $E_{-1}^{M P}=E_{-1}^{C B}$. Combining this fact with the result of part (i) of Theorem 4 we obtain $E_{0}^{M P}>E_{-1}^{M P}$. Given the positive derivatives stated above, this implies that $q_{1}^{M P}>q_{0}^{M P}$ and $z_{1}^{M P}>z_{0}^{M P}$, which by (8) leads to $E_{1}^{M P}>E_{0}^{M P}$. Continuing this line of argument sequentially, we obtain the Corollary's result on the growth of the quantity and the absolute quality of teachers, as well as of the quality of education $E_{t}^{M P}$ over time. The latter, according to (6), immediately implies that the college attendance ability cut-off $a_{t}^{* M P}$ declines over time.

It remains to prove that $\bar{a}_{t}^{M P}$ also declines over time. With reference to the above argument, it suffices to show that $\frac{\partial \bar{a}_{t}^{M P}}{\partial E_{t-1}^{M P}}<0$ for $\mathrm{t}=0,1, \ldots$.

According to (15), $\bar{a}_{t}^{M P}=a_{t}^{*}+A z_{t}^{M P}$, so

$$
\frac{1}{A} \frac{\partial \bar{a}_{t}^{M P}}{\partial E_{t-1}^{M P}}=-\frac{\theta_{t} B h^{*}}{\left(\theta_{t}(b+B)-1\right) A C\left(E_{t-1}^{M P}\right)^{2}}+\frac{\partial z_{t}^{M P}}{\partial E_{t-1}^{M P}}
$$

We rewrite equation (21) as $\left(z_{t}^{M P}\right)^{2}+z_{t}^{M P} \frac{2 B h^{*}}{\left(\theta_{t}(b+B)-1\right)(b+B) A C E_{t-1}^{M P}}=\tau_{t} J_{t}^{M P}$. Differentiating both sides and using (6) and (19) we obtain the following:

$$
\frac{\partial z_{t}^{M P}}{\partial E_{t-1}^{M P}}<\frac{B h^{*}}{\left(\theta_{t}(b+B)-1\right)(b+B) A C\left(E_{t-1}^{M P}\right)^{2}}+\frac{\tau_{t} B h^{*}}{2 z_{t}^{M P}(b+B) A C\left(E_{t-1}^{M P}\right)^{2}}\left(1-\frac{a_{t}^{* M P}}{A}\right)
$$

Substituting this in (A31) we obtain

$$
\frac{1}{A} \frac{\partial \bar{a}_{t}^{M P}}{\partial E_{t-1}^{M P}}<\frac{B h^{*}}{(b+B) A C\left(E_{t-1}^{M P}\right)^{2}}\left[-1+\frac{\tau_{t}}{2 z_{t}^{M P}}\left(1-\frac{a_{t}^{* M P}}{A}\right)\right]
$$

Now, according to (A20)

$$
\frac{1}{A} \frac{\partial \bar{a}_{t}^{C B}}{\partial E_{t-1}^{C B}}=\frac{B h^{*}}{(b+B) C\left(E_{t-1}^{C B}\right)^{2}}\left(-1+\frac{1}{z_{t}^{C B}} \frac{2 v\left(1-\tau_{t}\right)+\gamma}{2 v+\gamma} \frac{\tau_{t}}{1-\tau_{t}}\left(1-\frac{a_{t}^{*}}{A}\right)\right)
$$

By directly comparing the right-hand sides of this inequality and (A32) and using the facts $z_{t}^{M P}>z_{t}^{C B}, E_{t-1}^{M P} \geq E_{t-1}^{C B}$ for $\mathrm{t}=0,1, \ldots$ established in Theorem 4, we conclude that $\frac{\partial \bar{a}_{t}^{M P}}{\partial E_{t-1}^{M P}}<\frac{\partial \bar{a}_{t}^{C B}}{\partial E_{t-1}^{C B}}$. Therefore by Lemma $4 \frac{\partial \bar{a}_{t}^{M P}}{\partial E_{t-1}^{M P}}<0$ is true for $\mathrm{t}=0,1, \ldots$ 


\section{Appendix 2}

Glossary of Notation

\begin{tabular}{|c|c|}
\hline$n$ & Fraction of time devoted to acquiring advanced education \\
\hline$Y_{t}$ & Total output in the goods sector in period $t$ \\
\hline$w$ & Total Factor Productivity in goods production sector \\
\hline$L_{t}$ & Aggregate unskilled human capital in goods production in period $t$ \\
\hline$\tau_{t}$ & Labor income tax rate in period $t$ \\
\hline$M P$ & Merit pay regime \\
\hline$C B$ & Collective bargaining regime \\
\hline$T_{t}^{j}$ & Total government revenue in period $t$ for $j=M P, C B$ \\
\hline$A$ & Upper bound on innate ability \\
\hline$a(\omega)$ & The innate ability of individual $\omega$ \\
\hline$a_{t}^{* j}$ & Ability cut-off level for attending college in period $t$ for $j=M P, C B$ \\
\hline$h_{t}^{* j}$ & $\begin{array}{l}\text { Human capital attainment of the lowest ability college graduate in period } t \text { for } \\
j=M P, C B\end{array}$ \\
\hline$l_{t}(\omega)$ & Unskilled individual's level of human capital in period $t$ \\
\hline$h_{t}(\omega)$ & Skilled individual's level of human capital in period $t$ \\
\hline$H_{t}$ & Aggregate supply of skilled human capital in period $t$ \\
\hline$H_{t}^{y}$ & Aggregate supply of skilled human capital in goods production in period $t$ \\
\hline$\theta_{t}$ & $\begin{array}{l}\text { Goods production sector productivity augmentation of skilled human capital } \\
\text { (skill premium) in period } t\end{array}$ \\
\hline$I_{t}(\omega)$ & Wage income of individual $\omega$ \\
\hline$C$ & Productivity coefficient of compulsory basic education \\
\hline$E_{t}^{j}$ & Public first-stage education quality in period $t$ for $j=M P, C B$ \\
\hline$b$ & Coefficient of in-college depreciation of pre-college human capital. \\
\hline$B$ & Productivity coefficient of higher education \\
\hline$h^{*}$ & Human capital threshold for admission to college \\
\hline
\end{tabular}


$\Sigma_{t}^{j} \quad$ Set of individuals employed as teachers in period $t$ for $j=M P, C B$

$q_{t}^{j} \quad$ Aggregate teacher quality in period $t$ for $j=M P, C B$

$z_{t}^{j} \quad$ Total number of teachers (fraction of teachers in overall population) in period $t$ for $j=M P, C B$

$\gamma \quad$ Elasticity of the quantity of teachers in the production of basic education quality

$v \quad$ Elasticity of the quality of teachers in the production of basic education quality

$I_{t}^{C B} \quad$ Teacher salary in period $t$ under the collective bargaining regime

$a_{t}^{j} \quad$ The lowest ability level among teachers in period $t$ for $j=\{M P, C B$

$\underline{h}_{t}^{j} \quad$ The lowest human capital level among teachers in period $t$ for $j=M P, C B$

$\bar{a}_{t}^{j} \quad$ The highest ability level among teachers in period $t$ for $j=M P, C B$

$\bar{h}_{t}^{j} \quad$ The highest human capital level among teachers in period $t$ for $j=M P, C B$ 